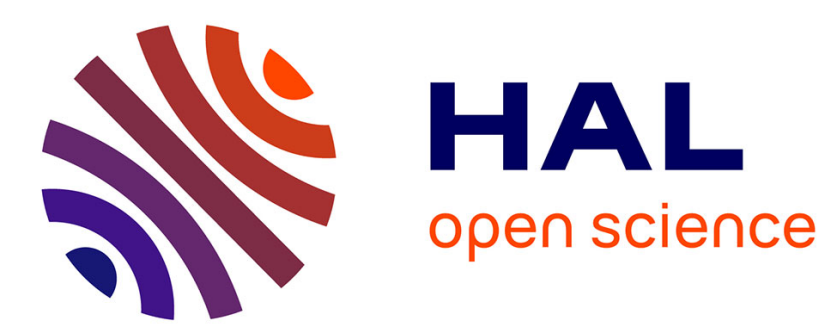

\title{
Ruthenium behavior in the reactor cooling system in case of a PWR severe accident
}

\author{
M.N. Ohnet, O. Leroy, A.S. Mamede
}

\section{To cite this version:}

M.N. Ohnet, O. Leroy, A.S. Mamede. Ruthenium behavior in the reactor cooling system in case of a PWR severe accident. Journal of Radioanalytical and Nuclear Chemistry, 2018, 316 (1), pp.161-177. 10.1007/s10967-018-5743-2 . hal-02871830

\section{HAL Id: hal-02871830 \\ https://hal.science/hal-02871830}

Submitted on 16 Jul 2020

HAL is a multi-disciplinary open access archive for the deposit and dissemination of scientific research documents, whether they are published or not. The documents may come from teaching and research institutions in France or abroad, or from public or private research centers.
L'archive ouverte pluridisciplinaire HAL, est destinée au dépôt et à la diffusion de documents scientifiques de niveau recherche, publiés ou non, émanant des établissements d'enseignement et de recherche français ou étrangers, des laboratoires publics ou privés. 


\section{Ruthenium behavior in the reactor cooling system in case of a PWR severe accident}

M. N. Ohnet, 1 四

Email marie-noelle.ohnet@irsn.fr

O. Leroy,

A. S. Mamede, 2

1 Institut de Radioprotection et de Sûreté Nucléaire (IRSN), PSNRES, Cadarache, Saint-Paul-Lez-Durance, 13115 France

2 Univ. Lille, CNRS, ENSCL, Centrale Lille, Univ. Artois, UMR 8181 - UCCS - Unité de Catalyse et Chimie du Solide, Lille, 59000 France

\section{Received: 20 November 2017}

\section{Abstract}

In the frame of severe accident topic for pressurized water reactor, the physical-chemistry of $\mathrm{Ru}$ fission products were experimentally studied to better understand their behavior inside the reactor coolant system in air or air/steam atmospheres. The tests consisted in vaporizing $\mathrm{RuO}_{2}$ at $1200^{\circ} \mathrm{C}$ and the ruthenium oxides are transported through a controlled thermal gradient tube made of quartz or preoxidized stainless steel. Results show that the major part up to $95 \%$ is deposited along the tube, the remaining part being transported almost under gaseous form attributed to $\mathrm{RuO}_{4}$. Impact of carrier gas, temperature profile and nature of the tube are discussed. AQ1

Keywords 
Source term

Severe accident

Ruthenium transport

Reactor cooling system

Kinetics

\section{Introduction}

In the frame of severe accident (SA) occurring in a pressurized water reactor (PWR), some specific accidents with air-ingress lead to very oxidizing conditions [1]. Powers et al. [2] made first a review of the possible consequences of such kinds of accidents in assuming an air ingress flow rate of $100 \mathrm{~mol} / \mathrm{s}$, through the core, for station blackout accident with a surge line rupture. For such conditions, ruthenium which is a fission product with high yield radiation can be released in significant amounts from the melt core fuel as exhibited by several experimental programs. We can cite the past VERCORS (1983-2002) $[3,4]$ and ongoing VERDON [5] analytical tests performed by the “Commissariat à l'Energie Atomique et aux énergies Alternatives" (CEA) where some specific tests in high oxidizing atmosphere show some Ru releases higher from $20 \%$ up to $70 \%$. A complete set of experimental data from CNL (Canadian National Laboratories) [6] also exists for $\mathrm{Ru}$ release from the fuel and confirm high releases for oxidizing conditions. These high releases result from formation of ruthenium oxides $\left(\mathrm{RuO}_{\mathrm{x}}\right)$ much more volatile than metallic ruthenium present in the fuel. It appears that the Ru release begins when fuel temperature reaches at least $2000{ }^{\circ} \mathrm{C}$ and it is promoted by high burn-up fuel. Once released, ruthenium can be transported through the RCS and reach the nuclear containment building.

Ruthenium can contribute significantly to radiological damage in the human body in the short and medium term due to its two isotopes ${ }^{103} \mathrm{Ru}$ and ${ }^{106} \mathrm{Ru}[7,8]$, if released in a significant amount to the environment. In addition to its high radiotoxicity, Ruthenium is of particular interest due its ability to form volatile oxides [9], noticeably $\mathrm{RuO}_{4}$ which is volatile at room temperature. In Chernobyl accident, the following fission products: Te, I and Ru were measured to be partially under 
gaseous forms [10] with the portion of ${ }^{103} \mathrm{Ru}$ in gaseous components made up $0.6-13 \%$, that of ${ }^{106} \mathrm{Ru}$ made up $2.7-16 \%$.

Chemical behaviour of ruthenium in the containment SA conditions was studied in the last decade $[11,12,13]$ and from these works it appears that $\mathrm{RuO}_{4(\mathrm{~g})}$ can exist in the containment with quite long half-life and with possible formation from $\mathrm{Ru}$ deposits on the inner walls. For safety analysis, source term uncertainties have been discussed/assessed and as a result the high temperature chemistry in the RCS and its impact on the source term has been ranked with high priority by the Severe Accident Research Priority working group of the FP7 SARNET2 (Severe Accident Research NETwork of excellence) project [14]. Further, revolatilisation of FPs deposited on the RCS and on the containment surfaces can also constitute a significant delayed source term which remains to be better understood. For Ruthenium, specific analysis [15] tend to show that radiological consequences will mainly depend on the amount of ruthenium transported, either under volatile form or aerosol in the containment. In the next section, available data in the literature on these phenomena are detailed. Next complementary experimental work carried out by the French "Institut de Radioprotection et de Sûreté Nucléaire" (IRSN) will be presented and discussed. $\mathrm{AQ2}$

\section{Literature review}

Recent experimental works $[16,17,18,19,20]$ dedicated to the transport of Ru through RCS conditions were performed by AEKI (Atomic Energy Research Institute (Hungary), now MTA EK) and VTT (Technical Research Centre of Finland) organisations. In addition, VTT and Chalmers University of Technology (Sweden) studied in collaboration (under NKS-R programme) the effect of airborne compounds on $\mathrm{Ru}$ transport and speciation [21, 22, 23]. Main insights from these works are reported. Tests are based on $\mathrm{Ru}$ feed through a tube with a thermal gradient.

From AEKI studies, the standard sample configuration was $1 \mathrm{~g} \mathrm{ZrO}$ with approximately $5 \mathrm{mg}$ of metallic ruthenium powder encapsulated in the $\mathrm{ZrO}_{2}$ matrix, in some cases the $\mathrm{Ru}$ was present in the form of 
powdered Mo-Ru-Rh-Pd alloy, and other elements (FP and $\mathrm{UO}_{2}$ ) were also sometimes added [16]. Ru samples were heated up to $1100{ }^{\circ} \mathrm{C}$ and a carrier gas flowing through the tube to transport $\mathrm{Ru}(0.17 \mathrm{Nl} / \mathrm{min})$; carrier gas was mainly air and sometimes moist air (5\% steam content). The tube used was made with different materials (quartz, alumina, zirconium and more or less oxidized stainless steel) and the size was quite small with an internal diameter of $4 \mathrm{~mm}$ and a length of $185 \mathrm{~mm}$. Test duration was fixed to $6 \mathrm{~h}$. The tests performed were demonstrative in nature and the main objective was to assess impact of experimental parameter on the Ru transported at low temperature under aerosol or gas forms, with both forms being measured.

The main results obtained are:

- A high Ru fraction ( $>80 \%$ of the released $\mathrm{Ru}$ ) was deposited into the tube, the major part at higher temperature (about $900-600{ }^{\circ} \mathrm{C}$ ); the remaining part was gaseous at the outlet $\left(25^{\circ} \mathrm{C}\right)$;

- With the quartz tube and dry air about $6 \%$ reached the outlet under $\mathrm{RuO}_{4(\mathrm{~g})}$, value enhanced for a SS pre-oxidised tube reached about $20 \%$. It has been attributed to a better heterogeneous phase decomposition of $\mathrm{RuO}_{4}$ and $\mathrm{RuO}_{3}$ into $\mathrm{RuO}_{2}$ by the quartz than by the SS surface.

- The Ru gaseous fraction was higher for wet air (5\% steam) than for dry air;

- For Ru transport, some chemical surface processes are surely involved and have to be considered.

Hungarian study devoted to the effects of different surfaces on the transport and deposition of ruthenium oxides [17] showed that the heterogeneous phase decomposition of $\mathrm{RuO}_{4}$ and $\mathrm{RuO}_{3}$ into $\mathrm{RuO}_{2}$ is catalyzed more efficiently by the quartz surface than by the stainless steel or alumina surfaces in air stream. Pre-oxidation of SS surfaces in steam had no significant effect on the ruthenium deposition.

In VTT tests $[18,19,20]$ and in the collaborative tests between VTT and Chalmers [21, 22, 23], the source of $\mathrm{Ru}$ was placed in an alumina 
crucible in the form of $\mathrm{RuO}_{2}$ powder or $\mathrm{Ru}$ was fed directly in the form of $\mathrm{RuO}_{4(\mathrm{~g})}$. The thermal gradient tube is made of SS with an internal diameter of $22 \mathrm{~mm}$ and a length of about $1000 \mathrm{~mm}$. The flow rate through the facility was mainly kept constant at $51 /$ min (NTP). Ruthenium dioxide was exposed to oxidising environment at high temperature $\left(827-1427^{\circ} \mathrm{C}\right)$ in a tubular flow furnace with dry air or moist air $(<10 \%$ steam for the major part of experiments). Experiment duration time was between 20 and $60 \mathrm{~min}$, except for the revaporisation tests which were longer (up to $360 \mathrm{~min}$ ). At the outlet, ruthenium particles as well as gaseous ruthenium were quantified. For some tests $\mathrm{Ru}$ was labelled in ${ }^{103} \mathrm{Ru}$ in order to measure the $\mathrm{Ru}$ profile deposit along the tube. The main results obtained depend on the experimental conditions, up to $26 \%$ of $\mathrm{Ru}$ was released under aerosol and gaseous forms at $1427^{\circ} \mathrm{C}$ and up to $6 \%$ as $\mathrm{RuO}_{4(\mathrm{~g})}$ at $1027^{\circ} \mathrm{C}$.

The main insights are:

- Humidity significantly increased the transport of ruthenium through the facility; mainly in the form of $\mathrm{RuO}_{2}$ aerosol with a decreased $\mathrm{RuO}_{4}$ fraction when compared to the dry air condition. At $1027^{\circ} \mathrm{C}$ when steam volume fraction was further increased (above 10\%) the transport rate decreased below that measured in dry air.

- Higher furnace temperature $\left(1427^{\circ} \mathrm{C}\right)$ promotes the aerosol formation and transport with respect to condensation processes onto surface;

- Persistence of $\mathrm{RuO}_{4(\mathrm{~g})}$ is promoted by alumina tube rather than a SS tube and also by the presence of $\mathrm{NO}_{2}$ gas (50 ppm) and CsI particles. The feed of $\mathrm{AgNO}_{3}$ droplets which are probably decomposed into silver and nitrous gas $\left(\mathrm{NO}_{\mathrm{x}}\right)$ resulted in a significant increase of $\mathrm{RuO}_{4}$ fraction, not as high as in the experiment with $\mathrm{NO}_{2}$ gas as the only additive. Ag particles alone decreased the $\mathrm{RuO}_{4(\mathrm{~g})}$ transport.

- From revaporization but limited to only three tests, the $\mathrm{RuO}_{4(\mathrm{~g})}$ fraction observed is low, less than $1 \%$ of the Ru deposit (1227 and 
$1427^{\circ} \mathrm{C}$ ). However, the ratio of $\mathrm{RuO}_{4} / \mathrm{RuO}_{2}$ transported increased significantly.

From these data, it can be sump up that gaseous ruthenium tetroxide is formed in a thermal gradient tube and can persist at temperature in the range of the containment temperature in SA conditions, it means around $100{ }^{\circ} \mathrm{C}$. Based on that, complementary information is needed to further develop a modelling concerning the chemical reactivity of ruthenium species through the RCS and to later implement it in severe accident simulation software.

IRSN launched experiments dedicated on Ru transport through a thermal gradient tube with two main specific objectives; the first being to study impact of steam in the gas mixture in relevant compositions because most of the past tests were performed in dry air or with a very low content in steam; and the second is to look at the revaporization processes which can happen and contribute to delayed releases; for that longer tests will be performed. Details are provided in the next section.

\section{Experimental}

The START (Study of the TrAnsport of RuThenium in the primary circuit) program is a part of the Source Term Evaluation and Mitigation (STEM) project [24] hosted by OECD/NEA/CSNI and operated by IRSN. The specificity is to provide a parametric study in which the effect of one single parameter can be precisely studied to be able to build later a mechanistic model which will be implemented in the ASTEC IRSN software package (Accident Source Term Evaluation Code [25]). The main experimental data to be measured are: amount and speciation of Ru species (gaseous and condensed forms) transported to the thermal gradient tube (TGT) outlet, amount of Ru deposits along the TGT as a function of the experimental conditions and amount of $\mathrm{Ru}$ transported during the revaporization phase from the deposits.

Hereafter are described the results obtained for six relevant experiments performed under different boundary conditions. The studied experimental parameters are the composition of the carrier gas (steam/air mixtures at various ratios), the thermal profile (abrupt or smooth) and the material of the TGT (quartz or stainless steel). The 
comparison of the results obtained for the vaporization and revaporization phases, respectively, allows estimating the potential effect of each parameter studied.

\section{Experimental set-up}

The START set-up was designed to be quite representative at a small scale of the thermal phenomena of a RCS. The air/steam composition used is representative of air-ingress scenario [1]. The START facility is schematized in Fig. 1. The device comprised a high temperature tubular furnace (Nabertherm, RS170/750/12 with $13 \mathrm{~cm}$ of thermal insulation at both ends) and a transport tube simulating the RCS. Two tubes were used: made of quartz (Q) and stainless steel (SS). While the SS tube was representative of the RCS, the Q tube allowed the determination of deposits along the tube; it is assumed that deposits are not dependent on the nature of the surface. The $\mathrm{Q}$ tube had an internal diameter of $30 \mathrm{~mm}$ (thickness of $2.5 \mathrm{~mm}$ ) and was $1.70 \mathrm{~m}$ long for an abrupt profile and $2 \mathrm{~m}$ long for a smooth profile. The materials of the SS tube were Inconel alloy 600 for the high temperature (HT) zone in the furnace and Stainless Steel 316L from the exit of the furnace to the TGT outlet. The characteristics of the SS tube were $1.80 \mathrm{~m}$ long and an internal diameter of $32.7 \mathrm{~mm}$ (thickness of $4.85 \mathrm{~mm}$ ). A pre-oxidation of the SS tube was performed before the test with the same thermal profile as the test (furnace at $1200{ }^{\circ} \mathrm{C}$ and an abrupt profile) and with a gaseous mixture of steam/argon during $8 \mathrm{~h} 30 \mathrm{~min}(\mathrm{steam}=65.0 \mathrm{~g} / \mathrm{h}$ and $\mathrm{Ar}=53.5 \mathrm{~g} / \mathrm{h}$ ). At the end of this phase, the steam oxidation at high temperature led to a partial oxidation of the tube inner surface (thin black powder). So, to avoid pollution of the $\mathrm{Ru}$ reagent in the crucible with metallic oxides from Inconel material, an alumina tube of internal diameter of $23 \mathrm{~mm}$ has been inserted in the SS tube in the furnace zone only.

\section{Fig. 1}

Scheme of the START facility with a quartz tube 


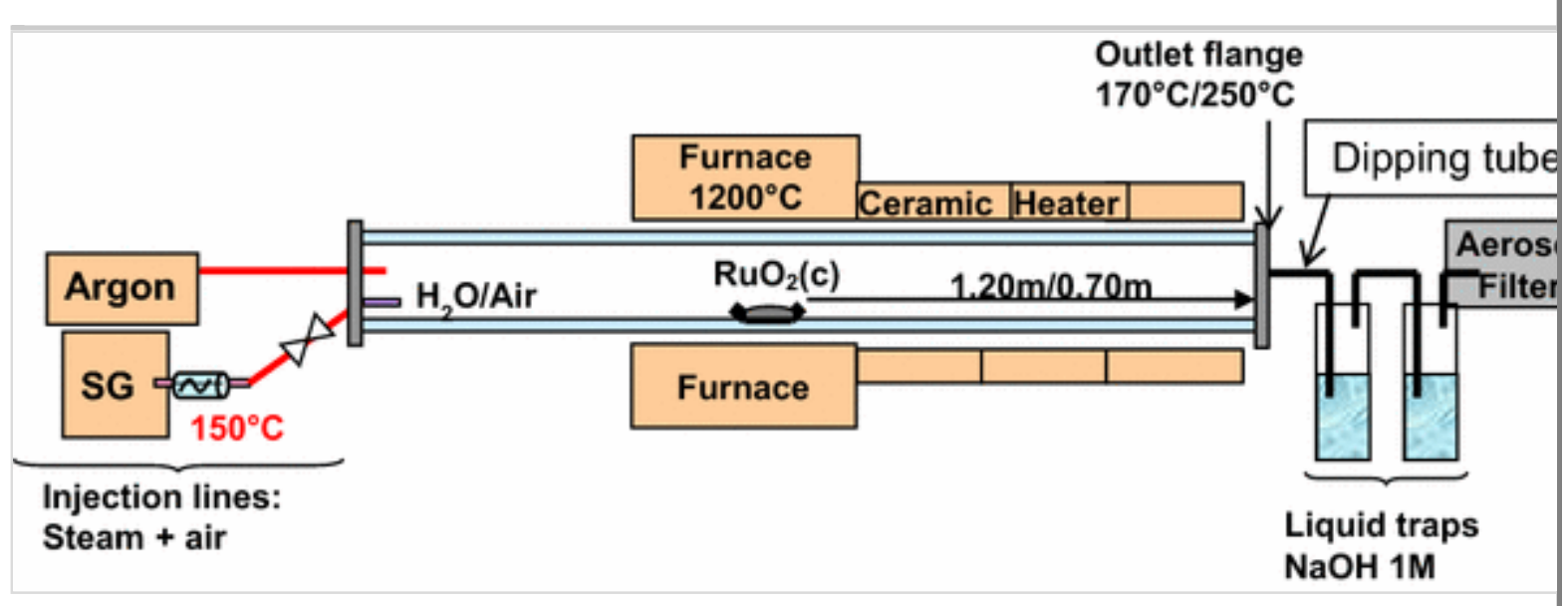

The facility was instrumented to enable on-line measurements and control of the thermal-hydraulic parameters (pressure, carrier gas flow rate, wall temperatures). The pressure in the line was around one bar. The gas mixture was introduced at $150{ }^{\circ} \mathrm{C}$ inside the transport tube. The steam generator ( $\mathrm{SG}$ ) allowed changing the composition of gas flow with different steam/air mixtures. For all the tests, the total flow rate was maintained constant at $1.84 \mathrm{Nl} / \mathrm{min}\left(0^{\circ} \mathrm{C}, 101,325 \mathrm{~Pa}\right)$ in order to have a similar residence time for a given temperature profile, thus only the steam/air ratio was an analytical parameter. Ceramic heaters were implemented between the outlet of the furnace and the tube outlet to regulate the wall temperature and control the temperature profile. Two different thermal profiles between 1200 and $250{ }^{\circ} \mathrm{C}$ (Q tube) or $170{ }^{\circ} \mathrm{C}$ (SS tube) were tested: an abrupt one with a strong decreasing temperature gradient (with a maximum temperature drop estimated to be $\left.\sim 27^{\circ} \mathrm{C} / \mathrm{cm}\right)$ and a smooth one with a less sharp gradient $\left(\sim 12^{\circ}\right.$ $\mathrm{C} / \mathrm{cm}$ ) (Fig. 2). During the commissioning tests, the thermal gradient between the high temperature zone and the tube outlet was experimentally measured with fluid and wall (top and bottom external) thermocouples. Thermal commissioning has been done with different gaseous mixtures (steam/air ratio). Only a negligible effect of steam has been observed on the two profiles, so it could be assumed that the profile was similar whatever the composition of the carrier gas was (in our range of experimental conditions). During the tests, the thermal gradient was measured by wall thermocouples only (upper ones). The residence time between the crucible and the tube outlet lays between 4 and $7 \mathrm{~s}$ (according to the thermal profile and the short or long tube configuration), which is quite well representative of an accident 
situation, although these experiments are in laminar flow while turbulent flow would be expected in SA.

\section{Fig. 2}

Fluid thermal profiles with crucible at position 0 (furnace temperature at $1200{ }^{\circ} \mathrm{C}$, air flow rate at $1.84 \mathrm{Nl} / \mathrm{min}$ )

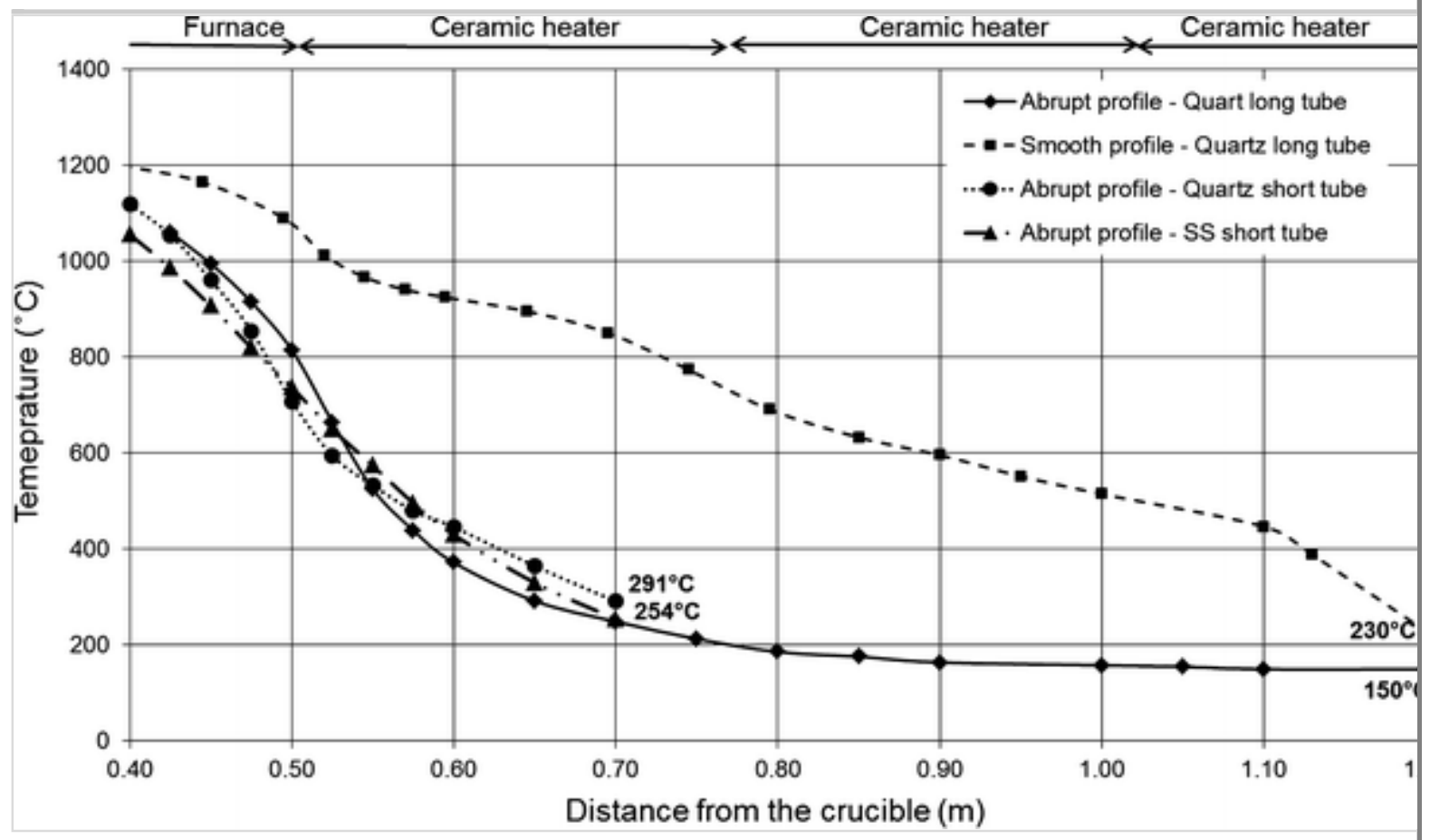

The ruthenium source was placed in an alumina crucible $\left(\mathrm{Al}_{2} \mathrm{O}_{3}, 99.7 \%\right)$ containing $1 \mathrm{~g}$ of anhydrous $\mathrm{RuO}_{2}$ powder (Alfa Aesar, purity 99.9\%). This crucible was located inside the furnace $\left(1200 \pm 10{ }^{\circ} \mathrm{C}\right)$. At $1200{ }^{\circ} \mathrm{C}$ and in air/steam mixture, $\mathrm{RuO}_{2}$ powder was mainly vaporized to $\mathrm{RuO}_{3}$ (g)

The outlet of the tube was equipped with two successive liquid traps to condense steam and trap ruthenium species. These traps were filled with an alkaline solution $(\mathrm{NaOH} 1 \mathrm{M})$ which traps gaseous ruthenium tetroxide species with a good efficiency [18]. The first liquid trap was cooled down (around $4{ }^{\circ} \mathrm{C}$ ) to improve the gaseous trapping [26], whereas the second one was at room temperature. In most of the cases, no gaseous $\mathrm{Ru}$ is detected in the second liquid trap, which confirms the efficiency of the cooled first trap. An ultimate filter (quartz fiber) was 
placed downstream to catch the potential remaining aerosols of $\mathrm{Ru}$ passing through the liquid traps.

\section{Experimental protocol}

Two phases were studied, a first phase called vaporization phase in which $\mathrm{Ru}$ was generated from a crucible and a second phase, called revaporization phase, performed without any source of Ru but in presence of Ru already deposited along the TGT. The typical thermalhydraulic experimental sequence for a START test is given in Fig. 3. For each vaporization test (with the crucible), the furnace was heated up to $1200 \pm 10{ }^{\circ} \mathrm{C}$ with a rate of $300{ }^{\circ} \mathrm{C} / \mathrm{h}$ under an inert gas (argon) flow. Then the temperature was maintained at $1200{ }^{\circ} \mathrm{C}$ during $1 \mathrm{~h}$ for thermal homogenization of the sampling tube, still under argon flow. After these $5 \mathrm{~h}$, argon was replaced by oxidative gas (air and/or steam as carrier gas) and the vaporization began. The duration of a test was about $7 \mathrm{~h}$ for the vaporization phase. At the end of the vaporization test, the furnace was stopped and the steam and air mixture was replaced by argon with the same flow rate $(1.84 \mathrm{N1} / \mathrm{min})$ during $10 \mathrm{~min}$ in order to stop $\mathrm{Ru}$ vaporization from the crucible. During the cooling down phase to room temperature, a low argon flow rate was used to sweep the tube. The next day, the argon flow was stopped to remove and to weigh the crucible containing the remaining reagent powder in order to assess the precise vaporized Ru mass.

\section{Fig. 3}

Thermal-hydraulic experimental sequences for a long duration START test 


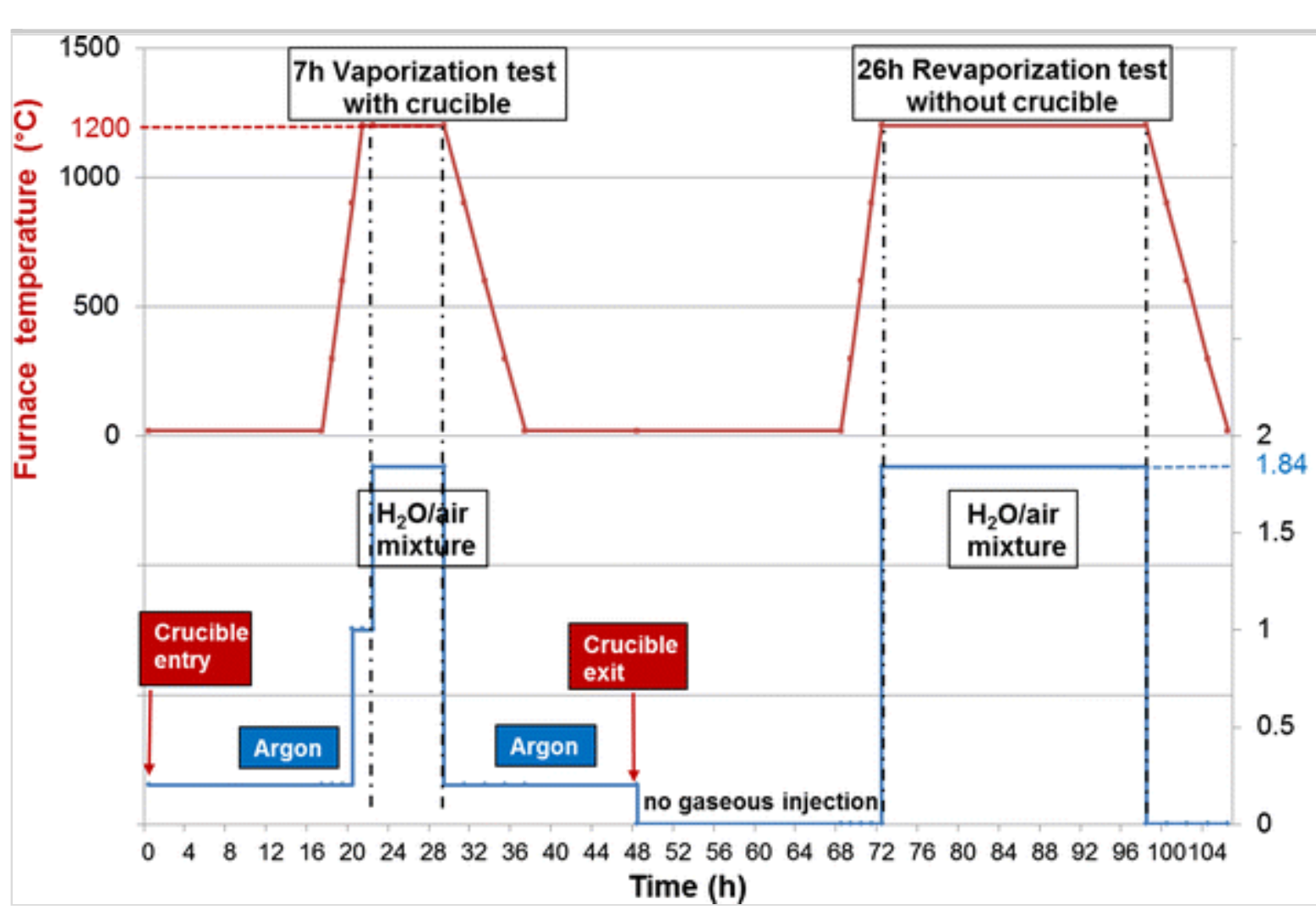

A revaporization phase was performed without reagent in the crucible but in presence of Ru deposits previously generated and with the same thermal-hydraulic conditions as those corresponding to the vaporization test. The revaporization test duration was between 10 and $29 \mathrm{~h}$ depending on the carrier gas used. For dry air, during the night, the thermal-hydraulic conditions were kept constant but no sampling was performed. In presence of steam, during the night, the carrier gas injection was stopped and the liquid traps were disconnected from the TGT, stored at low temperature $\left(4^{\circ} \mathrm{C}\right)$, while the furnace was maintained at $1200^{\circ} \mathrm{C}$.

\section{Experimental matrix}

The main test parameters were: the thermal profile (abrupt or smooth), the composition of gas flow (steam/air mixtures with $0 / 100 \%$ or $60 / 40 \%$ weight ratio) and the tube material (Q or SS). The START matrix is provided in Table 1 . Test 1 was the reference case with dry air condition (0/100\%), an abrupt thermal profile and a quartz tube. Test 2 focused on the effect of the steam/air ratio $\left(60 / 40 \%_{\mathrm{w}}\right)$. Tests 3 and 4 were dedicated to a less sharp thermal profile ("smooth") with dry air 
and steam-air mixture conditions respectively. Finally, the last two tests, numbered 5 and 6 , were performed with a pre-oxidized $316 \mathrm{~L} \mathrm{SS}$ tube. The composition of the carrier gas mixture $\left(60 / 40 \%{ }_{\mathrm{w}}\right)$ was $62.5 \mathrm{~g} / \mathrm{h}$ for steam mass flow rate and $41.8 \mathrm{~g} / \mathrm{h}$ for air mass flow rate.

Table 1

Experimental parameters of START tests

\begin{tabular}{|c|c|c|c|}
\hline Test & $\begin{array}{l}\text { Material, } \\
\text { thermal } \\
\text { profile }\end{array}$ & $\begin{array}{l}\text { Vaporization carrier } \\
\text { gas and duration }\end{array}$ & $\begin{array}{l}\text { Revaporization carrier } \\
\text { gas and duration }\end{array}$ \\
\hline 1 & Quartz, abrupt & Dry air, 7 h $30 \mathrm{~min}$ & Dry air, $26 \mathrm{~h}$ \\
\hline 2 & Quartz, abrupt & Steam + air, $7 \mathrm{~h}$ & $\begin{array}{l}\text { Steam }+ \text { air, } 4 \text { h } 30 \mathrm{~min} \\
\text { and air, } 22 \text { h }\end{array}$ \\
\hline 3 & Quartz, smooth & Dry air, $7 \mathrm{~h}$ & Dry air, $28 \mathrm{~h}$ \\
\hline 4 & Quartz, smooth & Steam + air, $7 \mathrm{~h}$ & $\begin{array}{l}\text { Steam }+ \text { air*, } 7 \mathrm{~h} \text { and air, } \\
22 \mathrm{~h}\end{array}$ \\
\hline 5 & $\begin{array}{l}316 \mathrm{~L} \text { SS } \\
\text { oxidized, } \\
\text { abrupt }\end{array}$ & Dry air, $7 \mathrm{~h}$ & Dry air, $28 \mathrm{~h}$ \\
\hline 6 & $\begin{array}{l}316 \mathrm{~L} \mathrm{SS} \\
\text { oxidized, } \\
\text { abrupt }\end{array}$ & Steam + air, $7 \mathrm{~h}$ & Steam + air, $12 \mathrm{~h}$ \\
\hline \multicolumn{4}{|c|}{$\begin{array}{l}\text { *During the period from } 150 \text { to } 270 \mathrm{~min} \text {, the gaseous mixture was } 36 / 64 \%_{\mathrm{w}} \text {, } \\
\text { contrary to the expected } 60 / 40 \% \%_{\mathrm{w}} \text { one and the total flow rate was only } \\
1 \mathrm{~N} 1 / \mathrm{min} \text { (leak on the entry flange of the tube). Nevertheless, this problem } \\
\text { should have a minor impact on the results }\end{array}$} \\
\hline
\end{tabular}

\section{$\mathrm{Ru}$ repartition}

For each test, the released ruthenium was collected at different locations. The main part of the $\mathrm{Ru}$ released was deposited in the transport tube and the remaining part reached the tube outlet under gaseous and aerosol forms. Aerosols were trapped on the dipping tube of the first liquid trap, in the first trap solution (in addition to the gaseous fraction) and on the ultimate filter (assumed to be only aerosols).

Source of $\mathrm{Ru}$ 
The Ru mass vaporized from the crucible, call later "crucible" vaporized Ru mass ("crucible" vap. Ru), was calculated by mass difference before and after the test. The initial $\mathrm{Ru}$ mass was obtained by the reagent analysis certificate ( $\sim 75 \%$ of the initial weight of product). The final amount of Ru was obtained indirectly by analysis of the percentage of oxygen (high temperature pyrolysis coupled to the oxygen quantitative analysis, uncertainty of $1 \%$ ). The Ru vaporization kinetics from the crucible was previously determined on calibration experiments for different test durations: from 20 to $420 \mathrm{~min}$ for a $60 / 40 \%{ }_{\mathrm{w}}$ steam/air ratio.

Deposits profile along the thermal tube

The deposits profile along the thermal tube was only measured on the quartz tubes (4 tests). After the test, the tube was radially cut in several pieces (about $2.5 \mathrm{~cm}$ ). This step induced some Ru losses (up to $20 \%$ of "crucible" vaporized Ru mass). The pieces were weighed, crushed and dissolved by alkaline fusion in order to analyze the ruthenium concentration by inductively coupled plasma-atomic emission spectrometry (ICP-AES). The uncertainty of the alkaline fusion process followed by ICP-AES analysis is $\sim 10 \%$ of the total amount of deposited $\mathrm{Ru}$ and the quantification limit (QL) is $\sim 10 \mathrm{ppm}(\sim 1 \mathrm{mg}$ for a $100 \mathrm{ml}$ sample).

\section{Raman and XPS investigation analyses}

The surface characterizations by X-ray Photoelectron Spectroscopy (XPS) and Raman spectroscopy of Ru deposits were performed. Raman scattering depends on electron-phonon interactions that are very sensitive to local environments. Raman scattering can provide information about the material or device structure on the scale of a few lattice constants and is probably the most useful method available for studying lattice vibrations and their interactions with other excitations. While the Raman spectroscopic technique can be used to gain insights into the microscopic structural effects of materials, XPS provides valuable complementary information on oxidation states and stoichiometry of Ru oxides. 
Micro-Raman spectra were obtained from a Renishaw spectrometer (RM1000 and in-Via model). Excitation was performed using the $514 \mathrm{~nm}$ green line of an argon-ion laser and the $785 \mathrm{~nm}$ of a near-IR laser, with a low power source (some $\mathrm{mW}$ ). The acquisition time was 30 $-100 \mathrm{~s}$ and the spectral resolution was $4 \mathrm{~cm}^{-1}$. The samples were pieces of quartz of test 3 (dry air).

The XPS analyses were performed using a Kratos Analytical AXIS Ultra $^{\text {DLD }}$ spectrometer using a monochromatic aluminum source $(\mathrm{A} 1 \mathrm{~K} \alpha=1486.6 \mathrm{eV})$ for excitation. The analyzer was operated in constant pass energy of $40 \mathrm{eV}$ using an analysis area of approximately $700 \mu \mathrm{m} \times 300 \mu \mathrm{m}$. XPS allows getting chemical composition with less than $10 \mathrm{~nm}$ depth scale of the surface. Quantification and decomposition of the experimental photopeaks were carried out using CasaXPS software. Quantification took into account a non-linear Shirley background subtraction whereas Gaussian G (70\%)-Lorentzian $\mathrm{L}(30 \%)$ product form or Lorentzian asymmetric LF line shapes were used for spectral decomposition of $\mathrm{C} 1 s, \mathrm{O} 1 s$ and Ru $3 d$, respectively. The fitting parameters of the LF line shape given in CasaXPS were derived from [27]. The XPS elemental composition has an accuracy of $\pm 10 \%$ and the detection limit is known to be 0.1 at.\%. Due to posttest surface analysis, surface contamination cannot be excluded. In order to have a basis, a reference sample $\left(\mathrm{RuO}_{2}\right.$ anhydrous reagent, purity $99.9 \%$, Alfa Aesar) was analyzed in the same conditions as described above. Some pieces of pre-oxidized 316L SS with Ru deposit after the revaporization tests (tests 5 and 6) and one piece of quartz (test 1) were characterized.

\section{Kinetic gas and aerosols partition study}

The kinetic evolution during the test was followed by analyzing periodically the liquid trap solution of the two traps by ICP-AES. The global uncertainty of the ICP-AES measurement was estimated at $10 \%$ and the detection limit at $10 \mathrm{ppb}$. In the second liquid trap, no Ru was detected.

The gaseous and some aerosol forms of $\mathrm{Ru}$ were trapped in the liquid traps while flowing through $\mathrm{Ru}$ aerosols were caught in the ultimate filter placed downstream of the sampling line. In the liquid trap, "outlet 
$\mathrm{Ru}$ " is gaseous $\mathrm{RuO}_{4}$ dissolved and aerosols in suspension. To determine the gaseous and aerosols partition, liquid trap solutions were centrifuged and filtered. Gaseous Ru forms in the solution were analyzed by ICP-AES and the filters with the aerosols from centrifuged solutions were dissolved by alkaline fusion in order to determine the $\mathrm{Ru}$ amount by ICP-AES analysis. So, the amount of Ru released under aerosol form was the sum of the Ru aerosol amount from the first liquid trap and from the ultimate filter.

In addition, a part of released $\mathrm{Ru}$ from the tube was also found on the dipping tube of the first trap. This deposit may result from aerosol deposit by impaction and also partly from the decomposition of $\mathrm{RuO}_{4(\mathrm{~g})}$ to $\mathrm{RuO}_{2(\mathrm{~s})}$ but probably in a lesser extent.

\section{Ruthenium mass balance}

For all the tests performed with a quartz tube, the Ru mass balance was evaluated by calculating the ratio of the "experimental" vaporized $\mathrm{Ru}$ mass which is the sum of the Ru collected amounts (deposits on the thermal tube and on the dipping tube, gas and aerosols in the liquid traps and aerosols on the ultimate filters) and the "crucible" vaporized Ru mass.

For the two tests with a SS tube, as the Ru deposit profile could not be determined, the amount of Ru deposits was deduced by the difference between the $\mathrm{Ru}$ amount vaporized from the crucible and the total $\mathrm{Ru}$ amount transported at the tube outlet (gas and aerosol in solution $+\mathrm{Ru}$ deposit on the dipping tube of liquid trap and on the ultimate filter).

\section{Results and discussion}

\section{$\mathrm{Ru}$ mass vaporization kinetics}

Analysis of the reagent (by X-Ray diffraction, see Fig. 4) showed that the final reagent is a mixture of crystallized $\mathrm{Ru}$ and $\mathrm{RuO}_{2}$ while the initial product is amorphous $\mathrm{RuO}_{2}$. As the composition of the final reagent ranges from 9 to $70 \%$ of $\mathrm{RuO}_{2}$ (Table 2), the vaporization rate could not be simply determined only from the reagent mass loss. This information was not presented in other studies [18]. 
Fig. 4

$\mathrm{X}$-Ray diffraction on $\mathrm{Ru}$ final product ( $\mathrm{Ru}$ metal in red and $\mathrm{RuO}_{2}$ in blue)

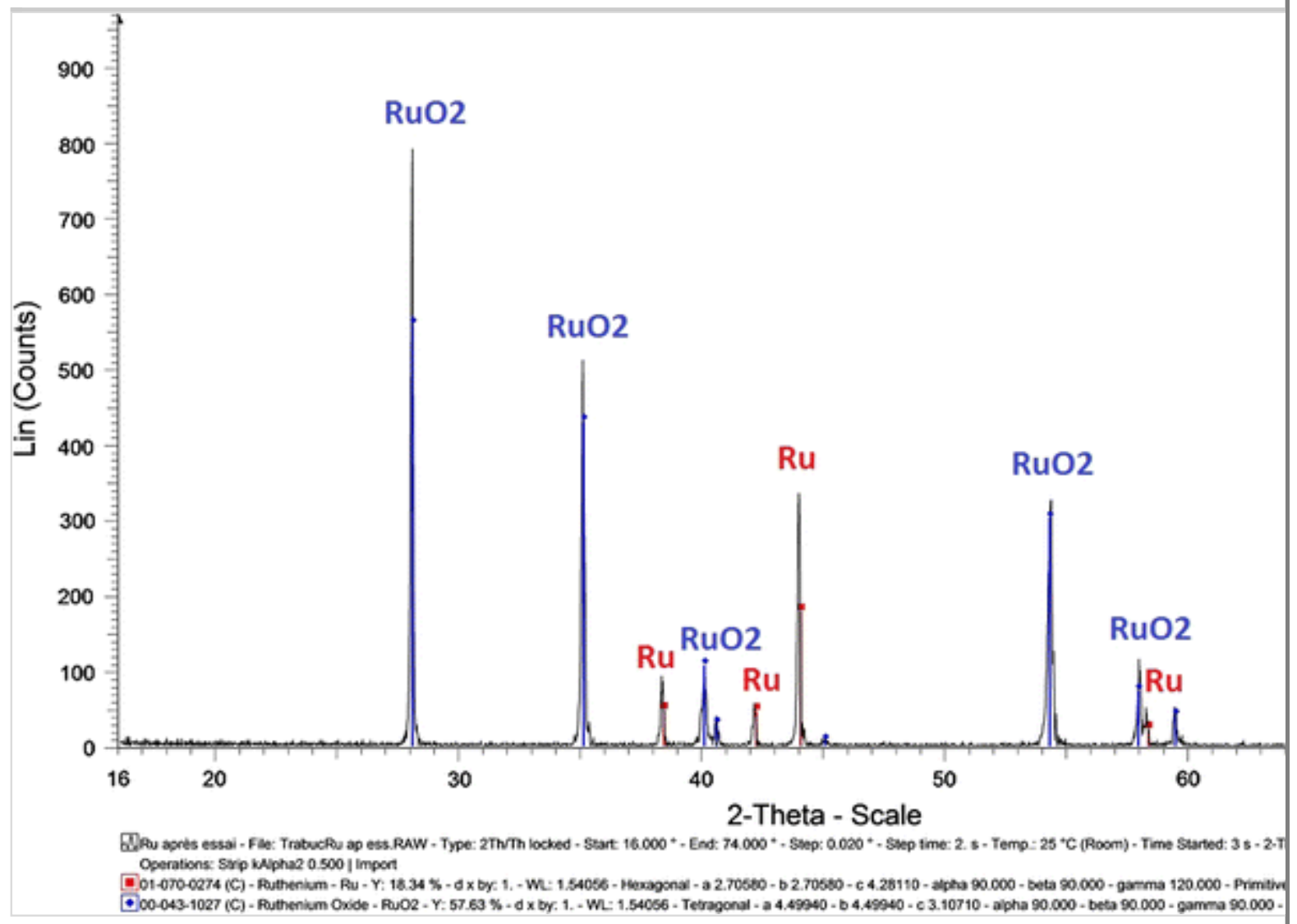

Table 2

Final reagent composition (Ru weight percent)

\begin{tabular}{|l|l|l|}
\hline Test & \% Ru & \% $\mathbf{R u O}_{\mathbf{2}}$ \\
\hline 1 & 65 & 35 \\
\hline 2 & 30 & 70 \\
\hline 3 & 80 & 20 \\
\hline 4 & 60 & 40 \\
\hline 5 & 91 & 9 \\
\hline 6 & 58 & 42 \\
\hline
\end{tabular}

In our protocol, the furnace was heated up to $1200 \pm 10{ }^{\circ} \mathrm{C}$ under an argon flow. So, the impact of this heating phase on the reagent was studied. Two heating phase tests (complementary tests) were performed 
to confirm the reproducibility of the vaporized Ru mass under argon. The pressure variation of the device and the $\mathrm{Ru}$ ultimate filter loading indicated that the vaporization of $\mathrm{Ru}$ starts around $700{ }^{\circ} \mathrm{C}$. At the end of the complementary tests, the mass reagent is up to $95 \%$ in metallic form and less than about $1 \%$ of initial Ru mass was vaporized from the crucible during this phase. So, during the preliminary $5 \mathrm{~h}$ heating phase under argon, the $\mathrm{RuO}_{2}$ powder in the crucible was reduced to $\mathrm{Ru}$ metal. To consider the oxidative phase only, the mass of Ru vaporized during the argon heating phase was removed from the measured vaporized $\mathrm{Ru}$ mass.

The $\mathrm{Ru}$ vaporization kinetic results showed no time dependence on the vaporization rate with $60 / 40 \%_{\mathrm{w}}$ condition. The rate was considered constant (Fig. 5) and reproducible ( $\pm 10 \%)$ for the other steam/air gas compositions. The total consumption of the Ru source $(1 \mathrm{~g})$ was never reached and allowed calculation of the vaporization rate. With the quartz tube, the mean values of the Ru vaporization kinetics have been calculated for the two steam/air gaseous mixtures used in the test matrix and for two additional conditions $35 / 65 \%_{\mathrm{w}}$ and $85 / 15 \%_{\mathrm{w}}$. Figure 5 displays that the mean value of the $\mathrm{Ru}$ vaporization rate is linearly steam/air mixture dependent. The dry air condition promotes $\mathrm{Ru}$ vaporization. The rate decreases by about $49 \%$ with decreasing air mass fraction from 100 to $15 \%$, consistent with Kärkelä et al. works [19] but nevertheless, vaporization rates obtained were ten times higher (for dry air) than ours. This is due to a higher flow rate $(5 \mathrm{l} / \mathrm{min})$ and a larger surface area of their crucible.

\section{Fig. 5}

$\mathrm{Ru}$ vaporization kinetics (a.u.) from the crucible as a function of the air weight ratio (quartz tube experiments only) 


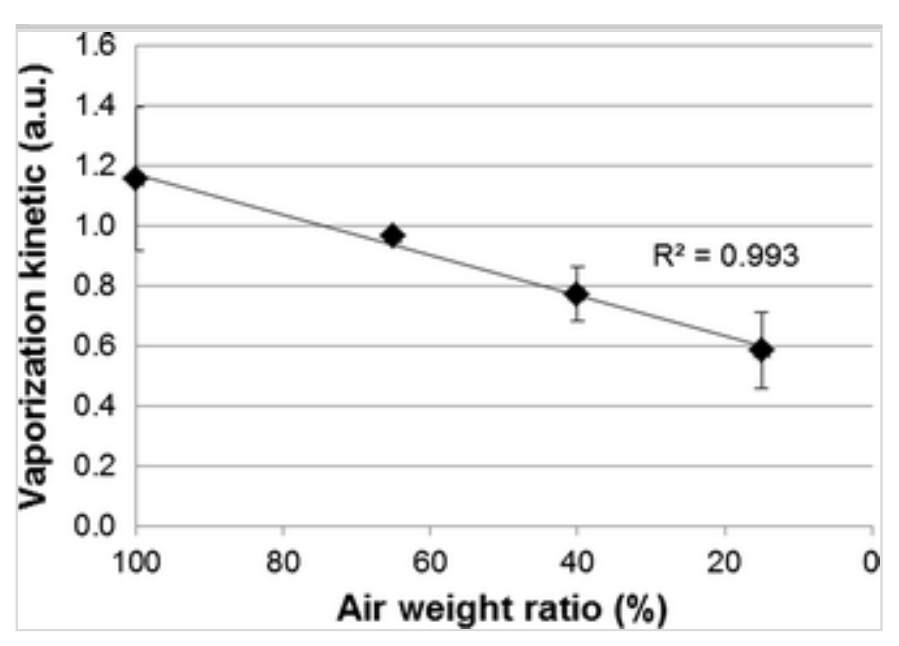

With the SS tube, the vaporization rates were slightly higher than those obtained with the quartz tube (20\% more). It could be explained by the reductions of the internal diameter of the tube in the HT zone and of the height of the crucible containing the reagent powder which have been changed due to geometrical constraint.

\section{Total ruthenium transported in vaporization and revaporization tests}

The results are summarized in Table 3 where the $\mathrm{Ru}$ amounts transported at the tube outlet (gaseous and total with aerosol fraction) for vaporization and revaporization phases are presented. All the data are expressed as \% of "crucible" vaporized Ru mass. Ru experimental mass balance based on $\mathrm{Ru}$ analysis reached about $80 \%$, the remaining part was mainly due to some losses due to the cutting process of the quartz tube.

\section{Table 3}

Results at tube outlet $\left(\sim 250^{\circ} \mathrm{C}\right.$, except for tests 5 and $6-\sim 170{ }^{\circ} \mathrm{C}$, outlet wall temperature) in \% of "crucible" vaporized Ru mass 


\begin{tabular}{|c|c|c|c|c|c|c|}
\hline \multirow{2}{*}{ Test } & \multicolumn{2}{|c|}{$\begin{array}{l}\text { Vaporization } \\
\text { phase }(\%)\end{array}$} & \multicolumn{2}{|c|}{$\begin{array}{l}\text { Revaporization } \\
\text { phase }(\%)\end{array}$} & \multirow{2}{*}{$\begin{array}{l}2 \\
\text { phases } \\
(\%) \\
\text { Ru } \\
\text { total }\end{array}$} & \multirow{2}{*}{$\begin{array}{l}\text { Measured Ru } \\
\text { tube deposit } \\
(\%)\end{array}$} \\
\hline & $\begin{array}{l}\mathrm{RuO}_{4} \\
\text { (gaseous) }^{\mathrm{a}}\end{array}$ & $\begin{array}{l}\mathbf{R u} \\
\text { total }\end{array}$ & $\begin{array}{l}\mathrm{RuO}_{4} \\
\text { (gaseous) }^{\mathrm{a}}\end{array}$ & $\begin{array}{l}\text { Ru } \\
\text { Total }\end{array}$ & & \\
\hline 1 & 1.3 & 2.8 & 0.6 & $1.1^{\mathrm{b}}$ & 3.9 & 71 \\
\hline 2 & 2 & 3.7 & 0.4 & 0.8 & 4.5 & 73 \\
\hline 3 & 0.2 & 0.9 & 0.3 & $0.5^{\mathrm{b}}$ & 1.4 & 79 \\
\hline 4 & 0.5 & 0.7 & 0.4 & $0.8^{\mathrm{b}}$ & 1.5 & - \\
\hline 5 & 0.3 & 3.2 & 0.3 & $0.3^{\mathrm{b}}$ & 3.5 & - \\
\hline 6 & 1.1 & 2.2 & 1.2 & $1.4^{\mathrm{b}}$ & 3.6 & - \\
\hline \multicolumn{7}{|c|}{ 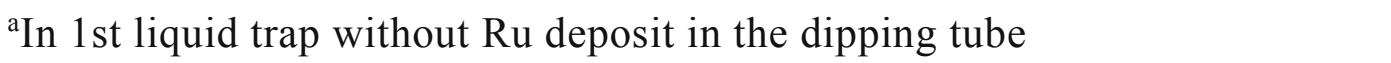 } \\
\hline
\end{tabular}

There is a clear effect of the thermal profile on the total Ru transported (gas, aerosols and deposit into dipping tube) during the vaporization and the revaporization phases. For tests with an abrupt profile (Quartz or SS tube) the total Ru transported represents from 3.5 to $4.5 \%$ of "crucible" vaporized Ru mass while it represents about three times less for the two smooth tests. So, whatever the gaseous composition and the tube material, the abrupt thermal profile promotes the total $\mathrm{Ru}$ amount transported at the outlet during vaporization and revaporization phases. The revaporization phenomena are not finished at the end of START experiments and the values obtained are not final values. During a hypothetical nuclear accident, the vaporization phase is a short term phenomenon while the revaporization phase should be a potential long continuous phase. So, revaporization from the Ru deposit in the RCS must be taken into account to calculate the total Ru amount transported to the containment in the long term.

\section{Transport during vaporization tests with the crucible}

Figures 6 and 7 show the evolution of the total $\mathrm{Ru}$ amount including gas and aerosol forms during the six tests. As with the work of Vér et al. 
with a low flow rate of $0.17 \mathrm{Nl} / \mathrm{min}[16,17]$, this study demonstrates that a part of $\mathrm{Ru}$ reached the outlet of the thermal gradient tube as gaseous $\mathrm{RuO}_{4}$ even if it is not expected by pure thermochemical computations.

Fig. 6

Evolution of the $\mathrm{Ru}$ amount (gas and aerosols) collected during vaporization tests

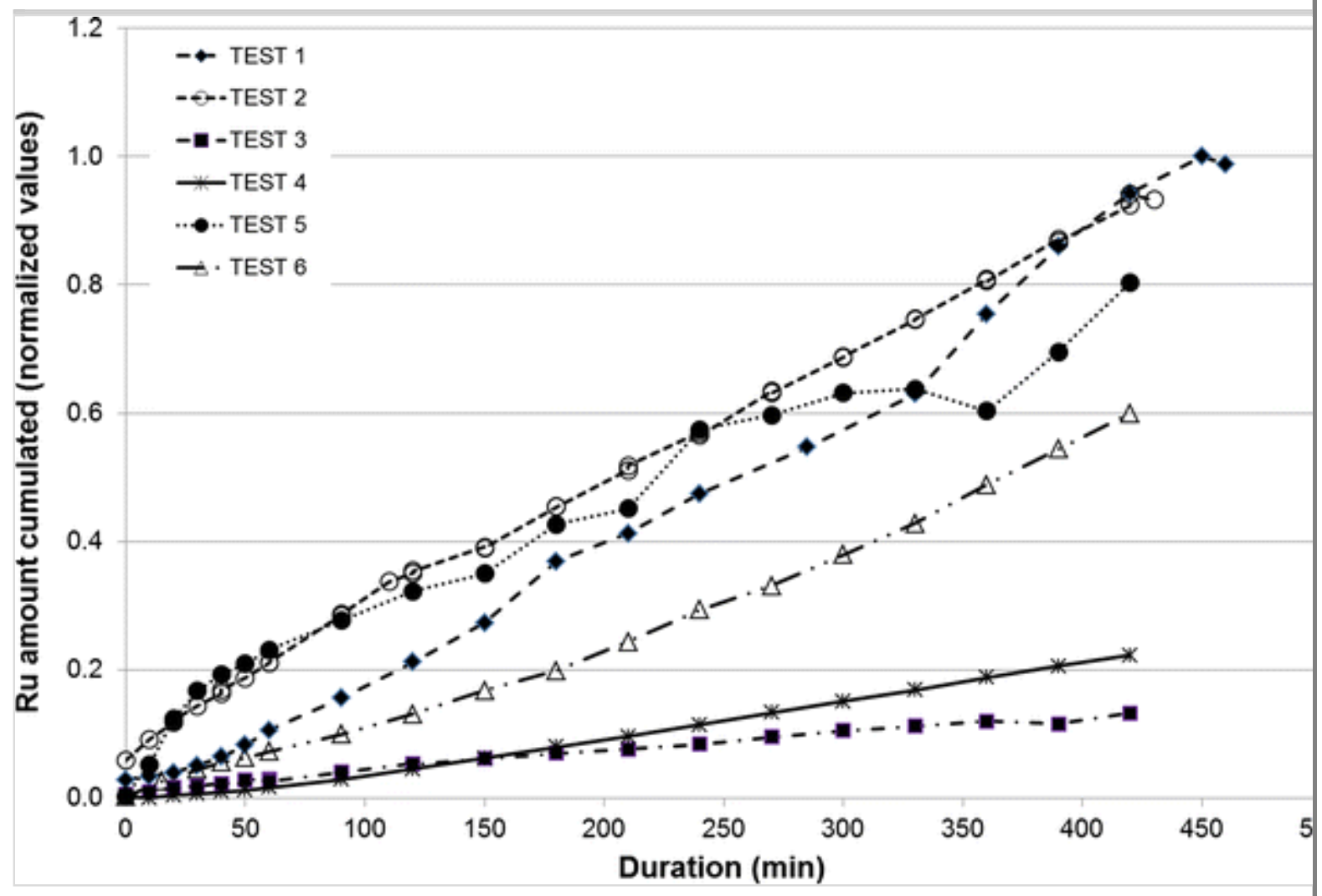

Fig. 7

Evolution of the gaseous $\mathrm{Ru}$ fraction as a function of the total vaporized $\mathrm{Ru}$ forms collected in the first liquid trap during the vaporization phase 


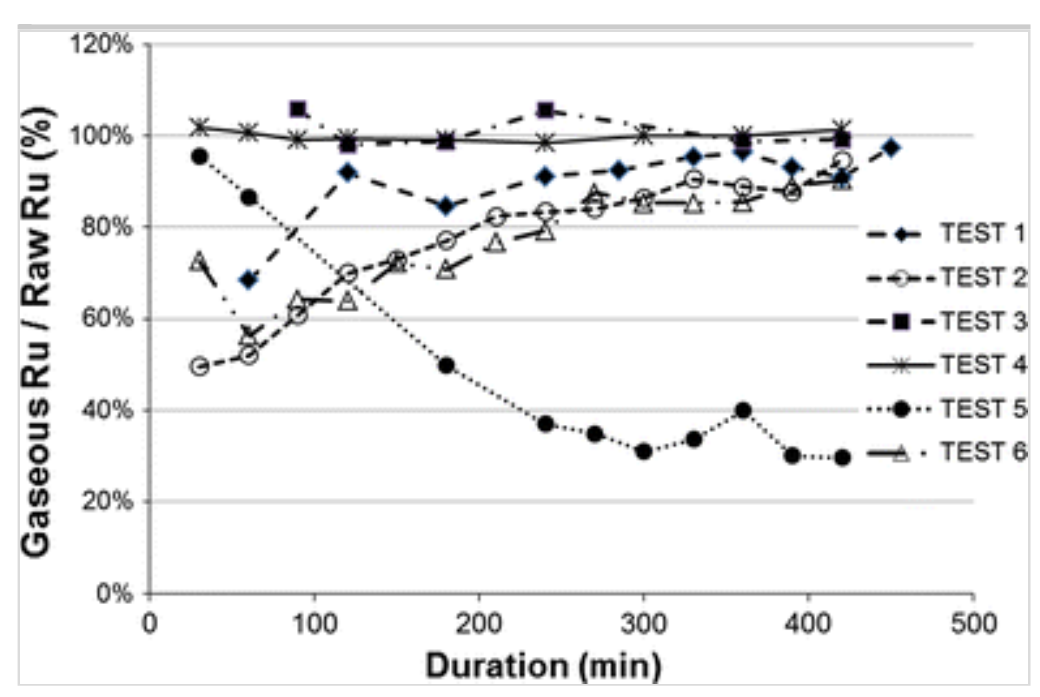

During the whole test duration, ruthenium transport kinetics (total amounts) were roughly linear. The lowest kinetic values of $\mathrm{Ru}$ transported at the tube outlet were observed for the smooth profile, especially in dry air. For the tests with an abrupt profile, there is no significant effect of the gaseous mixture and of the tube material on the transported Ru kinetics. As regards the gaseous evolution in the liquid traps (Fig. 7), for the test with a smooth profile, Ru transported to the tube outlet is only under gaseous form and with no aerosols measured. On the contrary, for the tests with abrupt thermal profile, whatever the tube material (SS/Q) and the gaseous mixture, there is a change in the gaseous/aerosols partition between the beginning and the end of the test. Globally, the $\mathrm{Ru}$ gaseous fraction increased significantly (except for test 5) and became the major contribution to the outlet Ru release. By contrast, for test 5 (SS, dry air), gaseous Ru is transported only during the first hour. Then the gaseous fraction was decreased by two thirds after $420 \mathrm{~min}$. Transient phenomena in the short term (in the first hour(s) of experiment) are clearly evidenced in this study and might explain these changes. Therefore, this switch of the species transported over the test duration should be taken into account when considering a long term reactor scenario.

According to Backman et al. [18] high cooling rates increased the $\mathrm{RuO}_{2}$ particle formation in the gas phase. In our study, except for test 5 (SS), aerosols were formed and transported at the outlet principally in the first hours of the experiment and decreased significantly in the course of the tests, possibly due to revaporization process of deposits. The 
aerosol formation and transport depend on the thermal profile but also to other parameters such as surface materials and/or gas flow rate/content.

Figure 8 presents the final partition of $\mathrm{Ru}$ transported in the gaseous form, $\mathrm{Ru}$ aerosols and $\mathrm{Ru}$ deposited into the dipping tube that should be attributed to aerosol phase. The total $\mathrm{Ru}$ amount transported to the tube outlet represents up to $3.7 \%$ of the "crucible" vaporized Ru mass after the vaporization phase (Table 3 ). The higher values of $\mathrm{Ru}$ transported (total and gaseous) at the tube outlet were observed for the abrupt profile compared to the smooth profile ( $\mathrm{x} 4$ ), linked mainly to kinetic limitations on $\mathrm{RuO}_{4(\mathrm{~g})}$ decomposition. Presence of steam promotes the gaseous Ru transported (black parts of columns in Fig. 8) whatever the tube material and the thermal profile. For the SS tube, Backman et al. proposed that the steam could passivate the stainless steel surface, hinder $\mathrm{RuO}_{2}$ deposition on the surface and promote the $\mathrm{Ru}$ gaseous transport. Indeed, in our study, the gaseous fraction is more important in presence of steam (test 6) compared to dry air (test 5).

\section{Fig. 8}

$\mathrm{Ru}$ gas, aerosols and deposits in the dipping tube at the end of vaporization tests (\% "crucible" vap. $\mathrm{Ru})$ as a function of the thermal profile (abrupt or smooth, quartz or SS tube). Tests 1,3 and 5 are in dry air, tests 2,4 and 6 are in $60 \%$ steam $/ 40 \%$ air mixture. Flow rate $1.84 \mathrm{Nl} / \mathrm{min}$

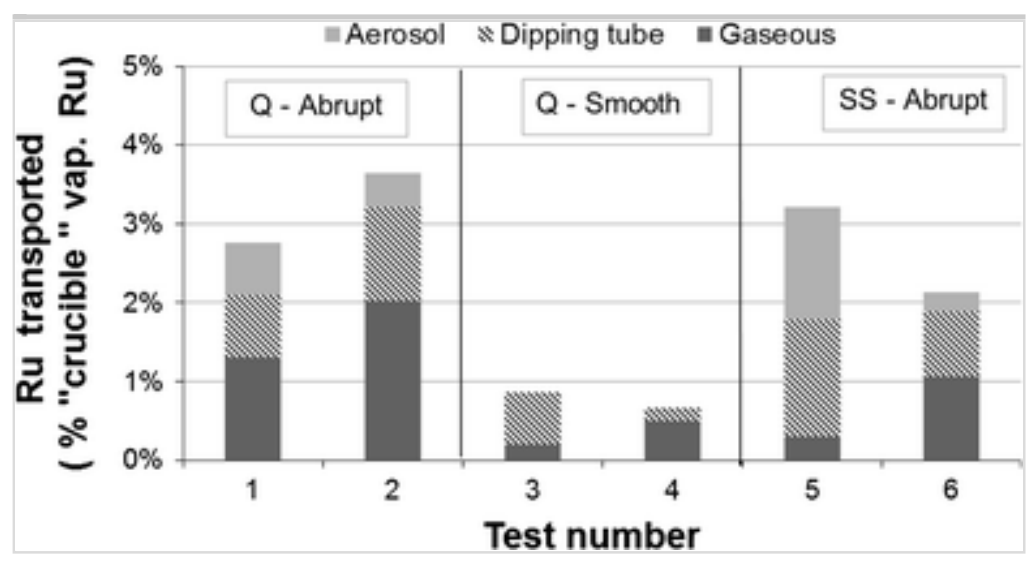

To check the reproducibility, the test in dry air with a smooth profile (test 3) was performed twice. The results showed good reproducibility 
of the vaporization tests results with a difference lower than $10 \%$ on the amount transported and kinetics, consistent with the expected uncertainties.

\section{Transport during revaporization tests}

The evolution of the Ru amount (gas and aerosols) in the first liquid trap during revaporization tests is shown in Fig. 9. For test 6, the gas (air + steam) injection was stopped during the night; the kinetic results obtained the next day were plotted just after those obtained the previous day. At the end of the experiments (12-29 h of revaporization), the revaporization phase was not finished. Kinetics were close to each other for all the tests, except for tests 1 and 6 with noticeably higher values. The total $\mathrm{Ru}$ amount transported to the tube outlet represents up to $1.4 \%$ of the "crucible" vaporized Ru mass for the revaporization phase (Table 3). As the total Ru transported at the tube outlet during the revaporization tests remains low, it is difficult to conclude on parametric effects but general trends can be highlighted.

\section{Fig. 9}

Evolution of the $\mathrm{Ru}$ amount (gas and aerosols) in the first liquid trap during long duration $(\mathrm{LD})$ revaporization tests 


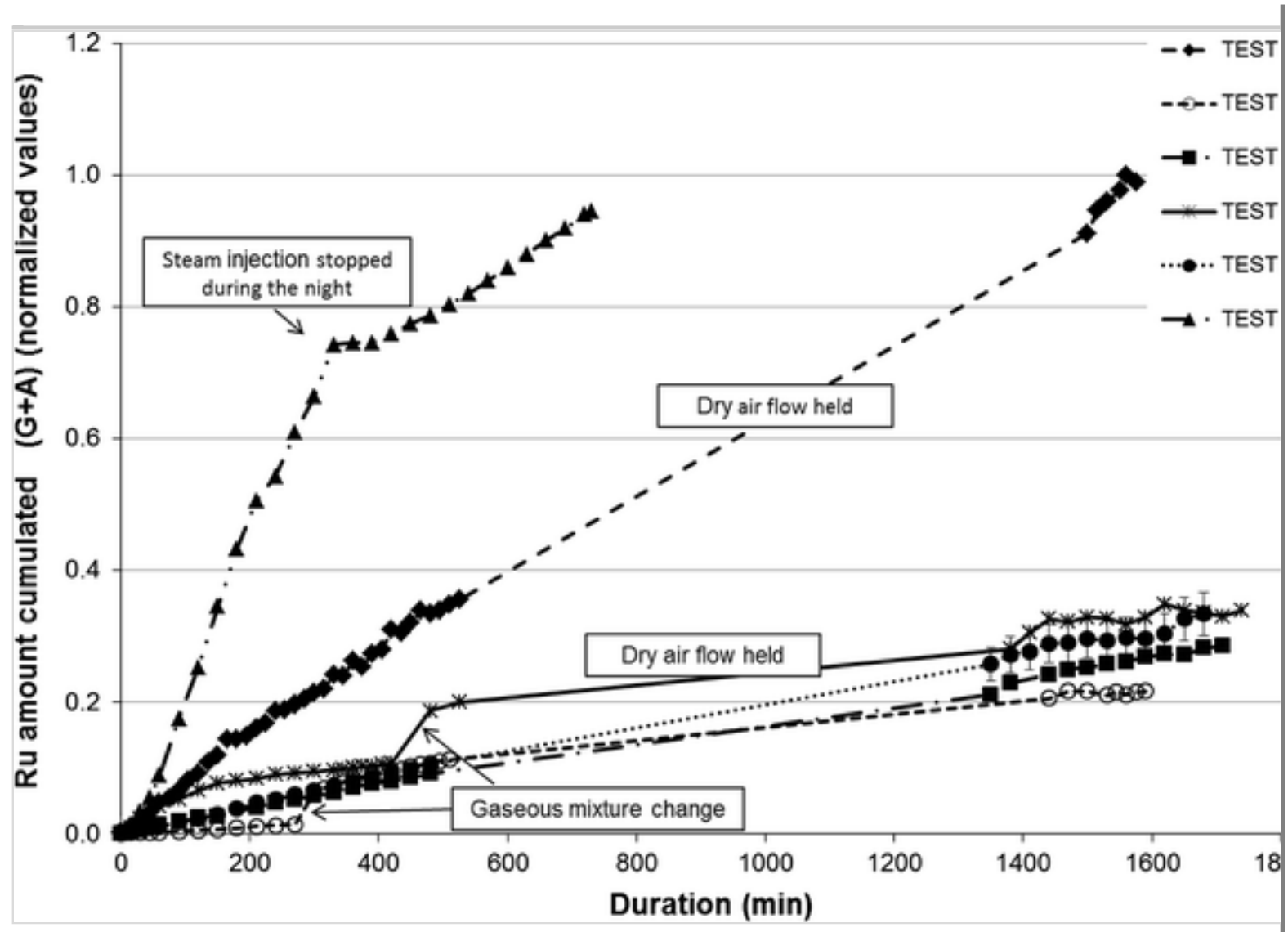

For dry air condition (tests 1, 3 and 5), whatever the material tube, the kinetics of $\mathrm{Ru}$ transport at the outlet is linear. Completion of the revaporization phenomenon could not be reached after $29 \mathrm{~h}$. In this study with dry air, the revaporization of deposited $\mathrm{RuO}_{2}$ from quartz was higher than from SS material, contrary to [17]. These differences could be attributed to the different experimental device (geometry and sampling tube). For steam conditions (tests 2, 4 and 6), a tube material effect is observed. Contrary to dry air condition, the gaseous Ru amount transported at the outlet is substantially promoted with the SS tube (by a factor of 6.4 after $12 \mathrm{~h}$ ). For test 6 with the SS tube (with the night stop), a decrease of the kinetic transport value the next day is observed (factor 4). So, the stop of injection of gas mixture has probably modified the conditions in the tube (Ru deposits) and could explain the lower revaporization kinetics observed. For quartz tube (tests 2 and 4), there is very little transport of Ru to the outlet tube. The change of carrier gas $(60 / 40 \%$ w to dry air) in tests 2 and 4 did not allow a resumption of the kinetics previously observed under dry air condition as in tests 1 and 3 respectively. This difference is most probably due to the effect of a steam excess on the Ru deposits. So it points out the 
importance of the gaseous mixture composition during the Ru deposit formation process, and consequently on the revaporization phase.

Contrary to the vaporization tests, no transient phase is observed in the short term during the revaporization tests.

During all the revaporization tests, $\mathrm{Ru}$ is transported mainly in a gaseous form to the tube outlet (Fig. 10). Therefore, the Ru deposit in the dipping tube originated principally from $\mathrm{RuO}_{4(\mathrm{~g})}$ decomposition to $\mathrm{RuO}_{2}$. For test 1 (air, quartz and abrupt profile), aerosol fraction (grey part of 1st column in Fig. 10) comes from the dipping tube leaching at the end of the experiment. Some aerosol deposit fell into the solution during manipulation and this fraction corresponds to a part of $\mathrm{Ru}$ deposit in the dipping tube. So to avoid this false attribution/assignment to aerosol, no leaching was performed on the other tests. Small amounts of aerosols are found on the ultimate filter in the tests with SS tube. However, these amounts represent less than $0.1 \%$ of the "crucible" vaporized $\mathrm{Ru}$ mass. With such low values $(<1.5 \%)$, it is difficult to conclude about the effect of the tube materials on the gas/aerosol partition. As the total Ru transported at the tube outlet during the revaporization tests remains in the same order of magnitude, it can be stated that the thermal profile (abrupt or smooth) has no significant effect on the revaporization whatever the gaseous mixture is (Fig. 10).

\section{Fig. 10}

$\mathrm{Ru}$ gas, aerosols and deposits in the dipping tube at the end of the long duration (LD) revaporization tests (\% "crucible" vap. $\mathrm{Ru}$ ) as a function of the thermal profile (abrupt or smooth), the tube material (Q or SS) and atmosphere (dry air: tests 1, 3, 5 and $60 \%$ steam/40\% air mixture: tests 2 , $4,6)$ 


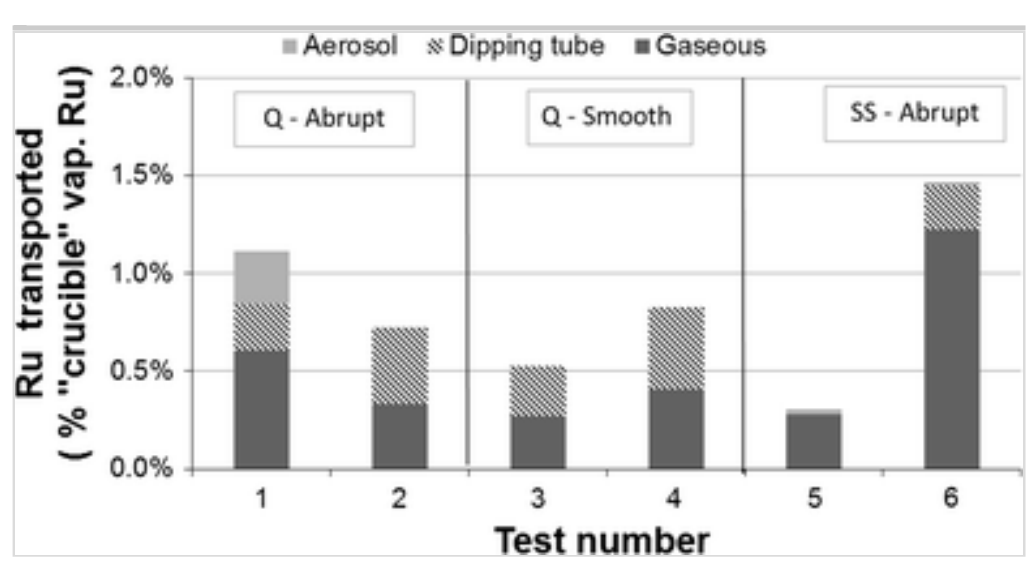

For revaporization tests, the kinetics are lower than for vaporization tests. This decrease could be due to the experimental protocol. After the vaporization test, the set-up is cooled down to ambient temperature in order to remove the crucible with reagent. For one revaporization test (test 6) the stop of the gaseous mixture during the night led to a decrease of the kinetic transport value the day after. So, the final $\mathrm{Ru}$ amount is under-estimated. This point should be investigated deeper in the future with an improvement of the current START experimental protocol.

\section{Deposit of ruthenium after revaporization}

The deposit profiles in a quartz tube were measured. Ru amounts deposited in the quartz tube after revaporization tests represent more than $90 \%$ of the "crucible" vaporized Ru mass. The deposited amount is a bit higher than literature data ranging from 65 to $94 \%[16,17,18,19$, $20,21,22,23]$. In our study, no influence of the tube material could be observed but the thermal-hydraulic conditions are quite different.

Figure 11 shows two different $\mathrm{Ru}$ deposit profiles obtained after vaporization and revaporization phases under the two steam/air gaseous mixtures and with an abrupt profile. The reported temperatures are upper wall temperatures at the middle of the cut quartz pieces for the steady state conditions. At a given distance from the crucible, the wall temperature is generally 5 or $10^{\circ} \mathrm{C}$ higher in the upper part than in the lower part of the tube and in any case this difference is lower than $20^{\circ}$ $\mathrm{C}$. The main part of the $\mathrm{Ru}$ deposit is located on the thermal gradient zone, between 1000 and $500{ }^{\circ} \mathrm{C}$. Ruthenium is deposited all along the 
quartz tube according to the temperature profile and mainly on the upper side of the tube, due to the thermal convection in the horizontal device with a laminar flow rate, a phenomenon also observed in [20]. The peak of $\mathrm{Ru}$ depositions happens at high temperature $\left(850 \pm 40^{\circ} \mathrm{C}\right)$, just after the outlet of the furnace, then the amount of deposited $\mathrm{Ru}$ decreases slowly down to the outlet $\left(\sim 250^{\circ} \mathrm{C}\right)$. This trend is similar to Vér et al. 's observations [17] where most of the Ru species were deposited on the quartz surface between 865 and $510{ }^{\circ} \mathrm{C}$. As already reported by [20], the bigger deposition peak at high temperature $\left(\approx \sim 1000-500{ }^{\circ} \mathrm{C}\right)$ could be due to the thermal dissociation of $\mathrm{RuO}_{3}$ into $\mathrm{RuO}_{2}$ followed by a smaller peak at lower temperature $\left(\approx \sim 500-250{ }^{\circ} \mathrm{C}\right)$ which could be due to reduction of $\mathrm{RuO}_{4}$ into $\mathrm{RuO}_{2}$. For the tests performed with a smooth profile, the Ru deposit is spread out all along the thermal gradient with a long tube. The major part of $\mathrm{Ru}$ deposits is the zone ranging from approximately $1000{ }^{\circ} \mathrm{C}$ down to $600{ }^{\circ} \mathrm{C}$.

\section{Fig. 11}

$\mathrm{Ru}$ deposit profiles after revaporization tests (1 and 2). Quartz tube with abrupt profile (1) dry air and (2) $60 \%$ steam $/ 40 \%$ air mixture
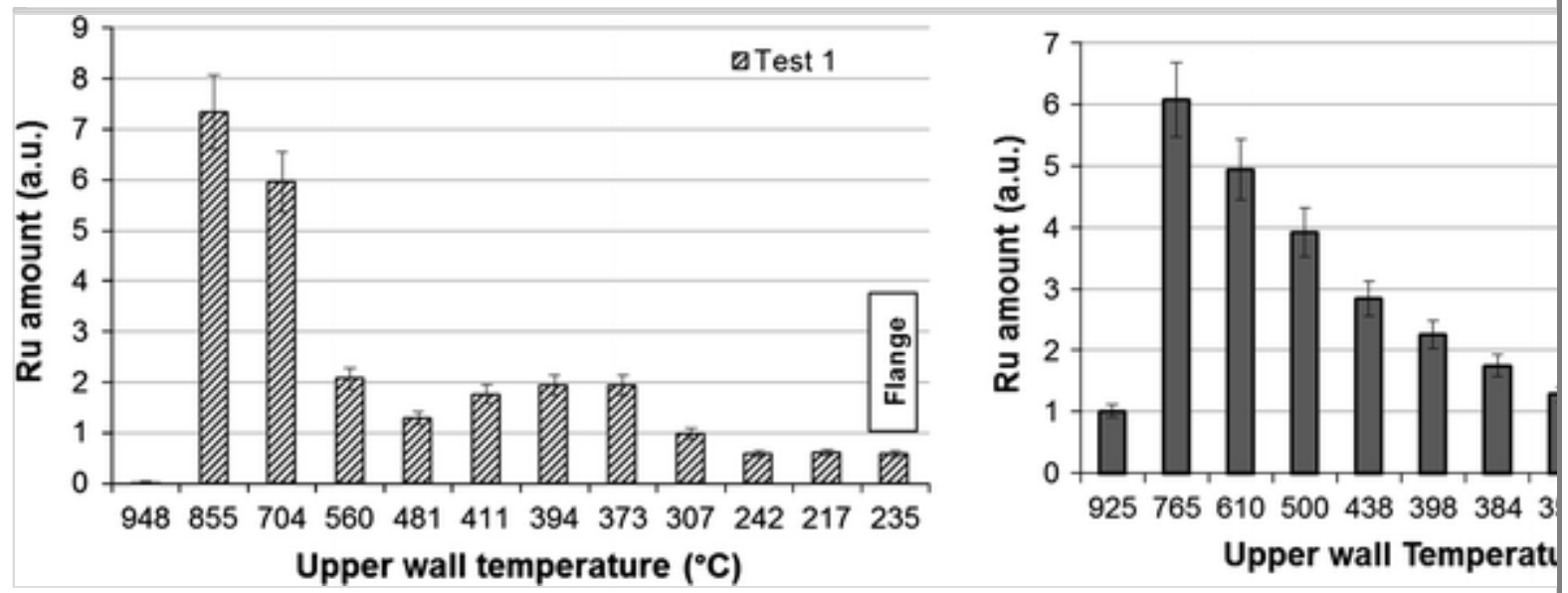

The comparison of the Ru deposit profiles in the quartz tube obtained after the vaporization phase and after the revaporization phase shows a shift of the $\mathrm{Ru}$ deposit to lower temperatures during the revaporization phase for all the gaseous mixtures. This trend is observed with a higher effect in the zone of high temperature for the dry air condition, where the $\mathrm{Ru}$ deposit in between $950 \pm 30^{\circ} \mathrm{C}$ to $880 \pm 30^{\circ} \mathrm{C}$ was completely revaporized according to visual observations (Fig. 12). This complete 
removal was not observed for the tests performed with steam/air mixtures. A comparison of the pieces of tube between 1000 and $500{ }^{\circ} \mathrm{C}$ for the two tests 1 and 2 shows that the Ru deposit is of different types, depending on the gas composition of the mixture studied. Especially for the condition with an excess of steam $\left(60 / 40 \%{ }_{\mathrm{w}}\right)$, the Ru deposit is thicker and has a foaming aspect (Fig. 13). This deposit appearance might come from the experimental protocol (injection of $100 \%$ dry air after the steam injection during the revaporization phase).

\section{Fig. 12}

$\mathrm{Ru}$ deposits after the vaporization (top) and the revaporization (bottom) test 1 (dry air, quartz tube and abrupt profile), with wall temperatures at the end of the revaporization test and distances from the crucible
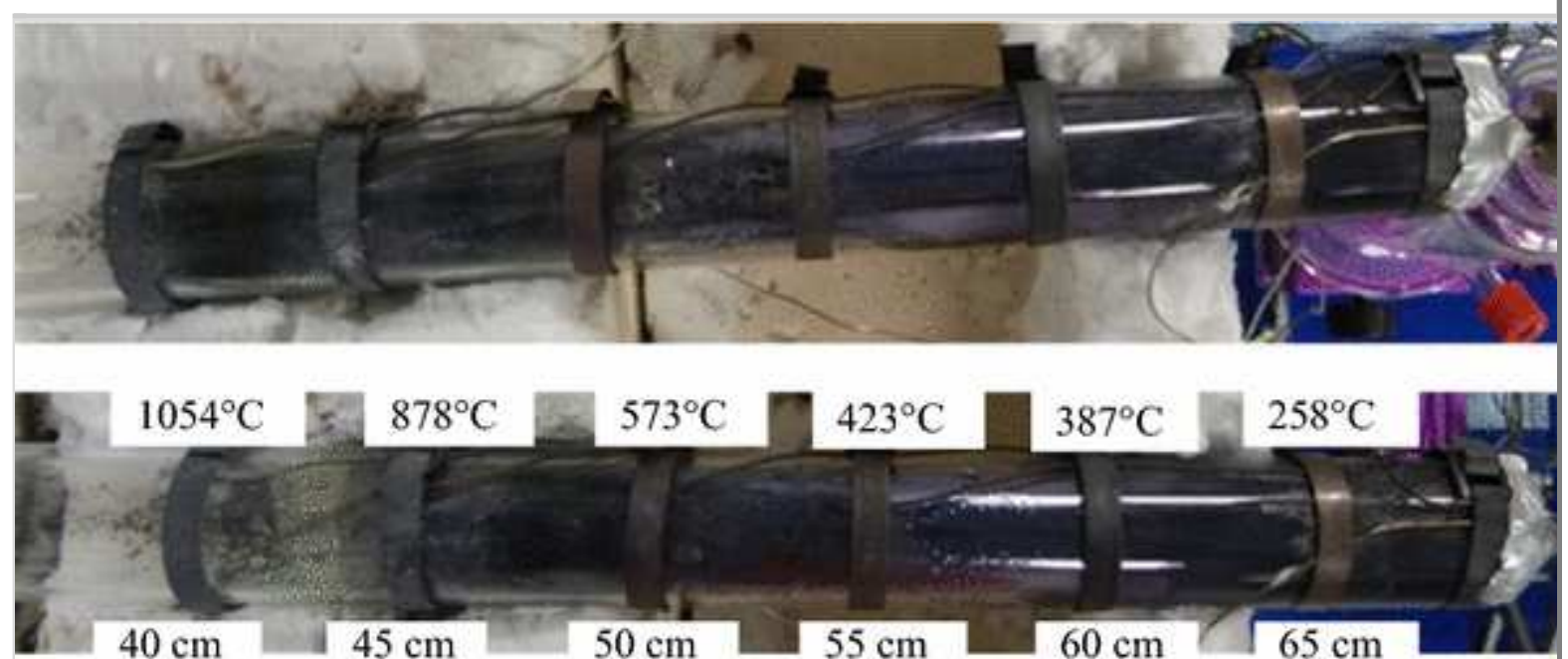

Fig. 13

Two quartz pieces with $\mathrm{Ru}$ deposits after the revaporization phase at the end of test 2 (left, between 850 and $700{ }^{\circ} \mathrm{C}$ and right, between 540 and $480{ }^{\circ} \mathrm{C}$ ) (quartz tube, abrupt profile, $60 \%$ steam $/ 40 \%$ air mixture) 

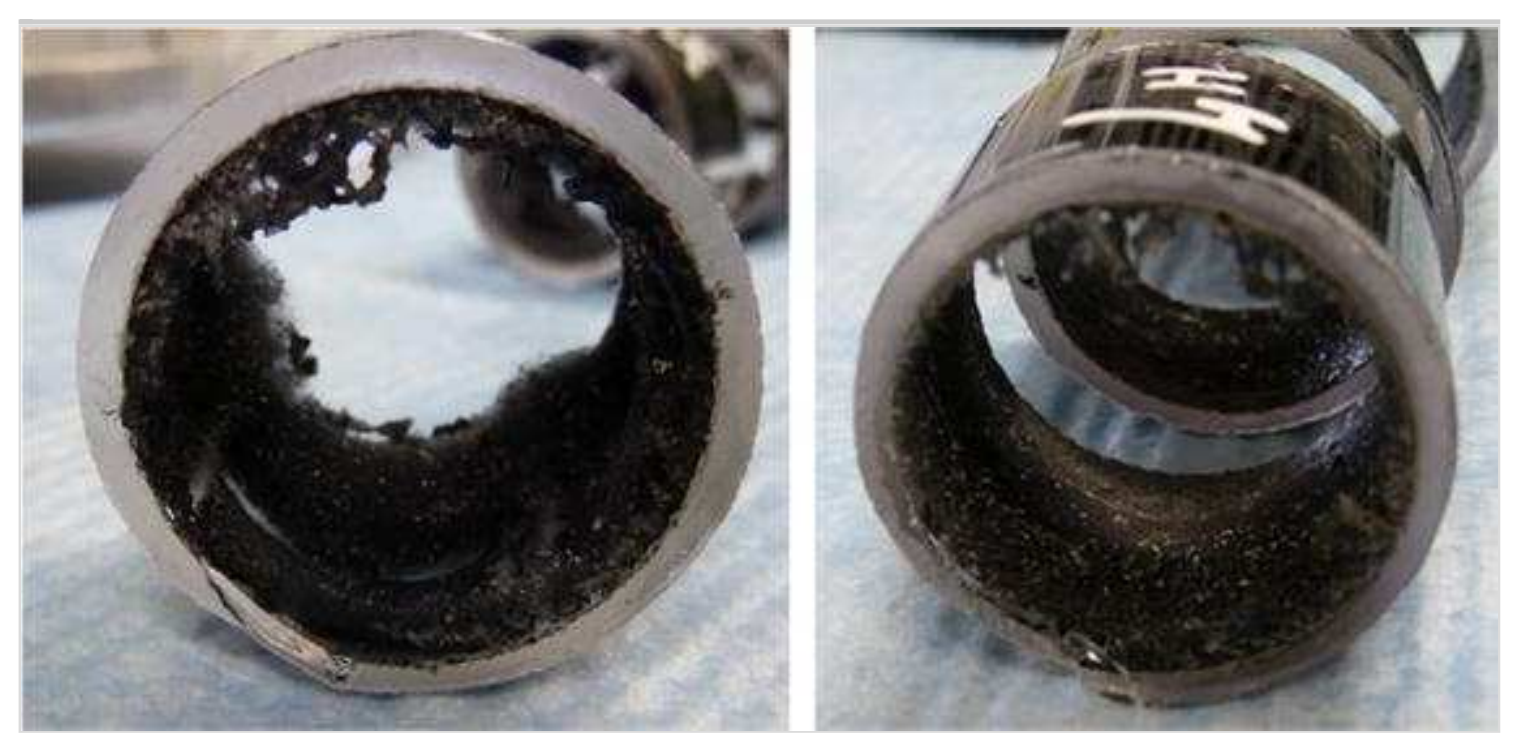

The results of surface characterization obtained by the Raman and XPS techniques show that, whatever the $\mathrm{Ru}$ deposit locations (at high temperature or at low temperature), the deposit is mostly formed of $\mathrm{RuO}_{2}$ species, except in two cases at about $880^{\circ} \mathrm{C}$ ( $\mathrm{Ru}$ metal, test 6 after vaporization phase with XPS results).

Raman spectra of Ru black deposit (temperature zone around $730{ }^{\circ} \mathrm{C}$, Fig. 14) and green deposit (around $275^{\circ} \mathrm{C}$ ) onto quartz pieces of test 3 $\left(0 / 100 \%_{\mathrm{w}}\right)$ show the three major bands of single crystal $\mathrm{RuO}_{2}$ which are located at 528, 646 and $716 \mathrm{~cm}^{-1}$ [28]. According to Music et al. [29], the shift and broadening of the Raman peaks for the $\mathrm{RuO}_{2}$ anhydrous reagent $\left(509,626\right.$ and $\left.689 \mathrm{~cm}^{-1}\right)$ are representative of less crystallinity and local disorder in comparison with the single crystal. The characteristic peaks of solid $\mathrm{RuO}_{4}$ are attributed near $880 \mathrm{~cm}^{-1}[30,31$, 32] and those of hydrous $\mathrm{RuO}_{2}$ at 470 and $670 \mathrm{~cm}^{-1}$ [32]. Room temperature Raman spectra of the $\mathrm{RuO}_{2}$ thin films on Si substrate, using the solution chemical technique, annealed at $700{ }^{\circ} \mathrm{C}$ show three major bands at about $523\left(E_{\mathrm{g}}\right), 646\left(\mathrm{~A}_{1 \mathrm{~g}}\right)$ and $710\left(\mathrm{~B}_{2 \mathrm{~g}}\right) \mathrm{cm}^{-1}$ [33]. An additional band at about $477 \mathrm{~cm}^{-1}$ was attributed by the authors to hydrated $\mathrm{RuO}_{2}$. It is generally known that $\mathrm{RuO}_{2}$ behaves as a hygroscopic oxide. To better understand the unassigned band at $477 \mathrm{~cm}^{-1}$, the temperature dependent behaviour of Raman spectrum was studied in detail by Bhaskar et al. [33].- This band appears at all temperatures below $27^{\circ} \mathrm{C}$ and disappears completely above the 
temperature of $77^{\circ} \mathrm{C}$, consistent with the assumption that the material transforms into the anhydrous form. The bands near $880 \mathrm{~cm}^{-1}$ and near $477 \mathrm{~cm}^{-1}$ are not observed for the samples in the current study, which confirms that these samples are characteristic of anhydrous $\mathrm{RuO}_{2}$.

\section{Fig. 14}

Raman spectra of black Ru deposit on quartz tube at around $730{ }^{\circ} \mathrm{C}$ (test 3 with $100 \%$ dry air condition) and $\mathrm{RuO}_{2}$ powder (initial reagent)

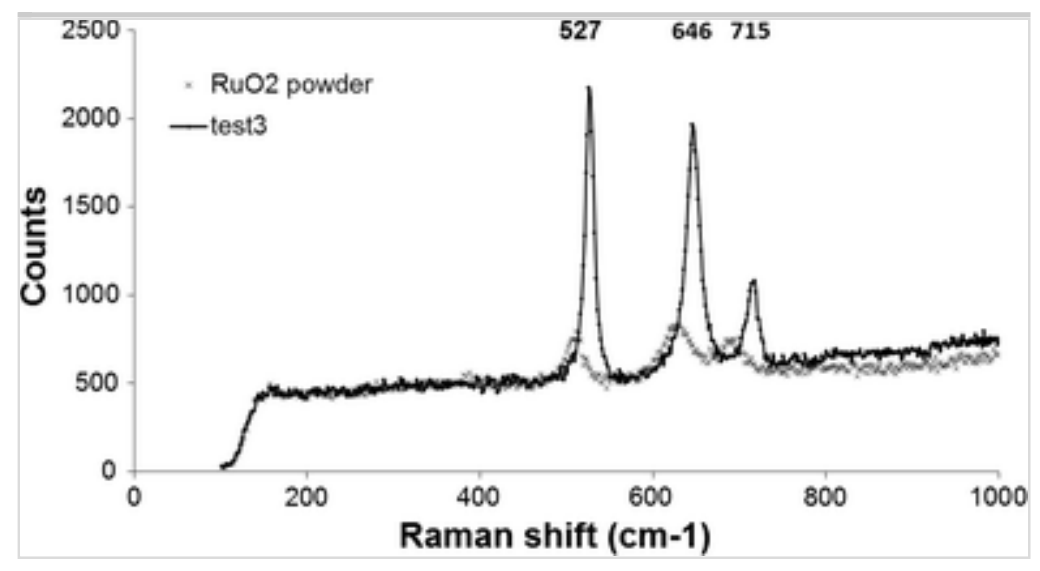

In general the XPS approach was found to be valuable in monitoring the surface concentrations of the ruthenium oxides and thus in characterizing their chemical compositions [34]. Nevertheless, the characterisation is rather complex because $\mathrm{Ru} 3 d$ peaks are overlaid by C $1 s$ peaks which come from carbon surface contamination (BE at $284.6 \mathrm{eV}$ ). Figure 15 shows XPS spectra of black Ru deposits on a piece of stainless steel from START test 5 after vaporization phase (dry air, corresponding temperature at about $430 \pm 15^{\circ} \mathrm{C}$ ). The binding energy (BE) of the $\mathrm{Ru} 3 d_{5 / 2}$ core level is pointed out at $280.5 \mathrm{eV}$, and at $529.1 \mathrm{eV}$ for the O $1 s$ peak. The sample from revaporization phase shows similar values (280.3 and $529.2 \mathrm{eV}$, respectively). Theses values of $\mathrm{Ru} 3 d_{5 / 2} \mathrm{BE}$ are in full agreement with the values cited in previous literature for anhydrous $\mathrm{RuO}_{2}$, ranging between 280.7 and $281.0 \mathrm{eV}$ [32]. It is known that $\mathrm{RuO}_{2}$ behaves as a hygroscopic oxide and the $\mathrm{BE}$ of the $\mathrm{Ru} 3 d_{5 / 2}$ peak of hydrated ruthenium dioxide is pointed out at $281.4 \mathrm{eV}$ [34] or at $282.3 \mathrm{eV}$ [35]. In a recent study [27], the difference between anhydrous and hydrated $\mathrm{RuO}_{2}$ was explored. Experimental 
$\mathrm{Ru} 3 d_{5 / 2}$ BE were found at 280.6 and $280.8 \mathrm{eV}$ respectively, and at 529.3 and $530.9 \mathrm{eV}$ for the $\mathrm{O} 1 \mathrm{~s}$ peak.

Fig. 15

XPS spectra of (a) Ru $3 d$ and (b) O $1 s$ core level lines of Ru deposit on SS for test 5 with $100 \%$ dry air condition (after vaporization test)
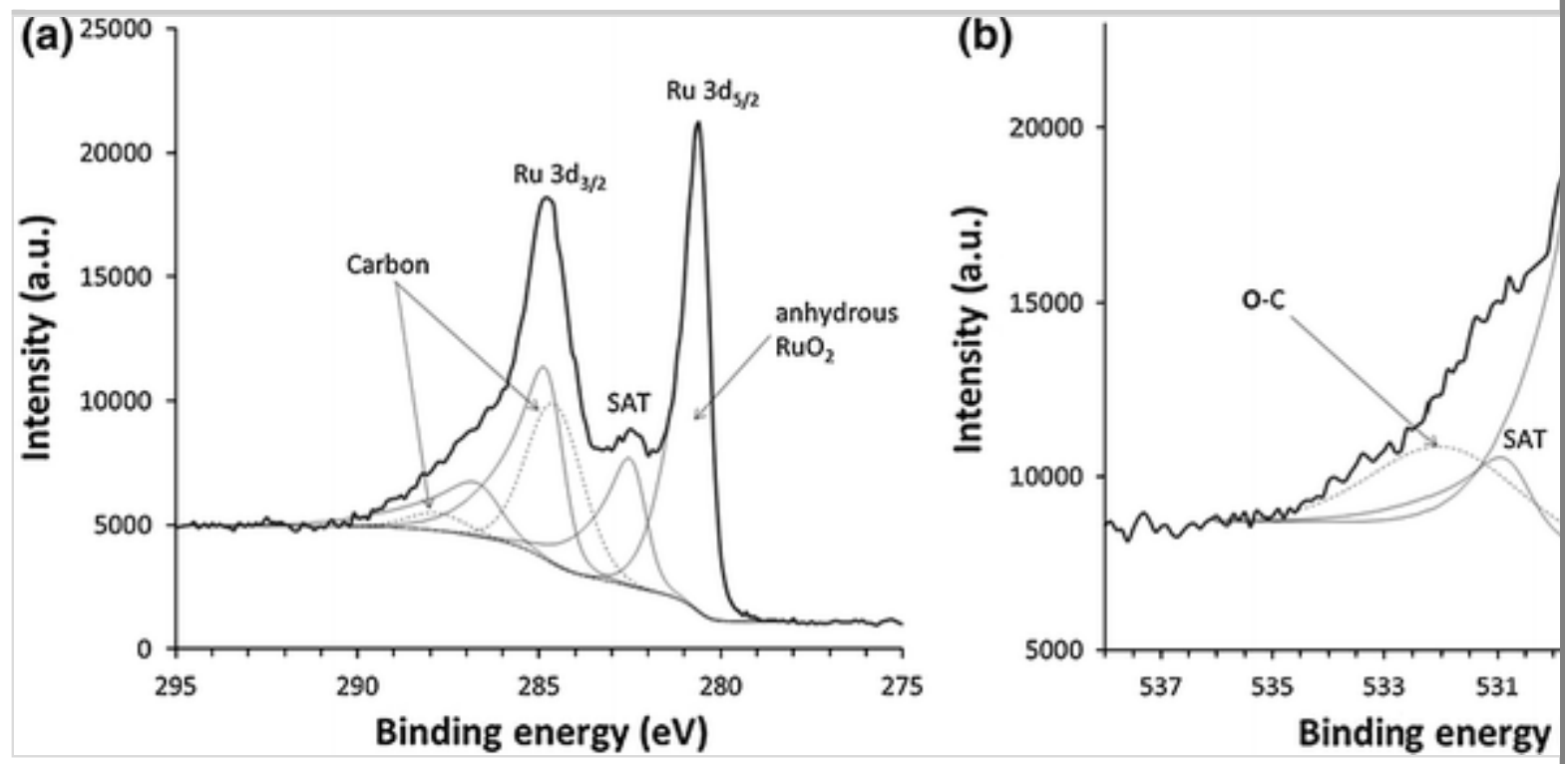

The $\mathrm{Ru}$ layers deposited on a piece of stainless steel were analysed by Mun et al. [35]. The BE of the Ru $3 d_{5 / 2}$ level was pointed out at $281.4 \mathrm{eV}$ and the $\mathrm{O} 1 s$ region was completely dominated by the hydroxyl component, results characteristic of $\mathrm{RuO}_{2} \cdot \mathrm{x}-\mathrm{H}_{2} \mathrm{O}$. The decomposition of the $\mathrm{O} 1 \mathrm{~s}$ peaks could be studied in a classical way, using three components (BE at around 529, 530.5 and $532 \mathrm{eV}$ ) attributed to oxygen atoms in three chemical environments: $\mathrm{O}^{2-}, \mathrm{OH}^{-}$ and $\mathrm{H}_{2} \mathrm{O}$, associated respectively to lattice oxygen, hydroxyl groups and water adsorbed at the surface of $\mathrm{RuO}_{2}$ [13]. The presence of chemisorbed oxygen on the film surface could be associated with hydrated $\mathrm{RuO}_{2}$ or $\mathrm{RuO}_{3}$. As reported in [33], during the film preparation, the relatively rapid cooling process undergone by the film after deposition enhances the formation of $\mathrm{RuO}_{3}$ species on the surface. The characteristic $\mathrm{BE}$ of $\mathrm{RuO}_{3}$ are pointed out at 282.7 and $531.0 \mathrm{eV}$ for the $\mathrm{Ru} 3 d_{5 / 2}$ and $\mathrm{O} 1 s$, respectively. Kim and Winograd [34] found that $\mathrm{RuO}_{3}$ exists as a stable surface species on anhydrous $\mathrm{RuO}_{2}$, as a defect structure. Two samples (upper and lower) of test 6 after vaporization, 
corresponding to a temperature of about $880 \pm 20^{\circ} \mathrm{C}$, show a spectrum characteristic of $\mathrm{Ru}$ metal (53-62\%) with a $\mathrm{Ru} 3 d_{5 / 2}$ peak at $279.8 \mathrm{eV}$ [34], and with BE Ru $3 d_{5 / 2}$ at $280.3 \mathrm{eV}(47-38 \%)$ and $\mathrm{BE} \mathrm{O} 1 s$ at $529.7 \mathrm{eV}$ characteristic of anhydrous $\mathrm{RuO}_{2}$ (Fig. 16). One sample (upper layer) of test 6 after revaporization (near $560{ }^{\circ} \mathrm{C}$ ) shows only peaks of anhydrous species (BE Ru $3 d_{5 / 2}$ at $280.3 \mathrm{eV}$ and $\mathrm{BE} \mathrm{O} 1 s$ at $529.0 \mathrm{eV})$.

Fig. 16

XPS spectra of a, $\mathbf{c} \mathrm{Ru} 3 d$ and $\mathbf{b}, \mathbf{d} \mathrm{O} 1 s$ core level lines of Ru deposit on SS for test 6 with $60 / 40 \%{ }_{w}$ mixture (after vaporization test $\mathbf{a}$, b, and after revaporization test $\mathbf{c}, \mathbf{d}$ )
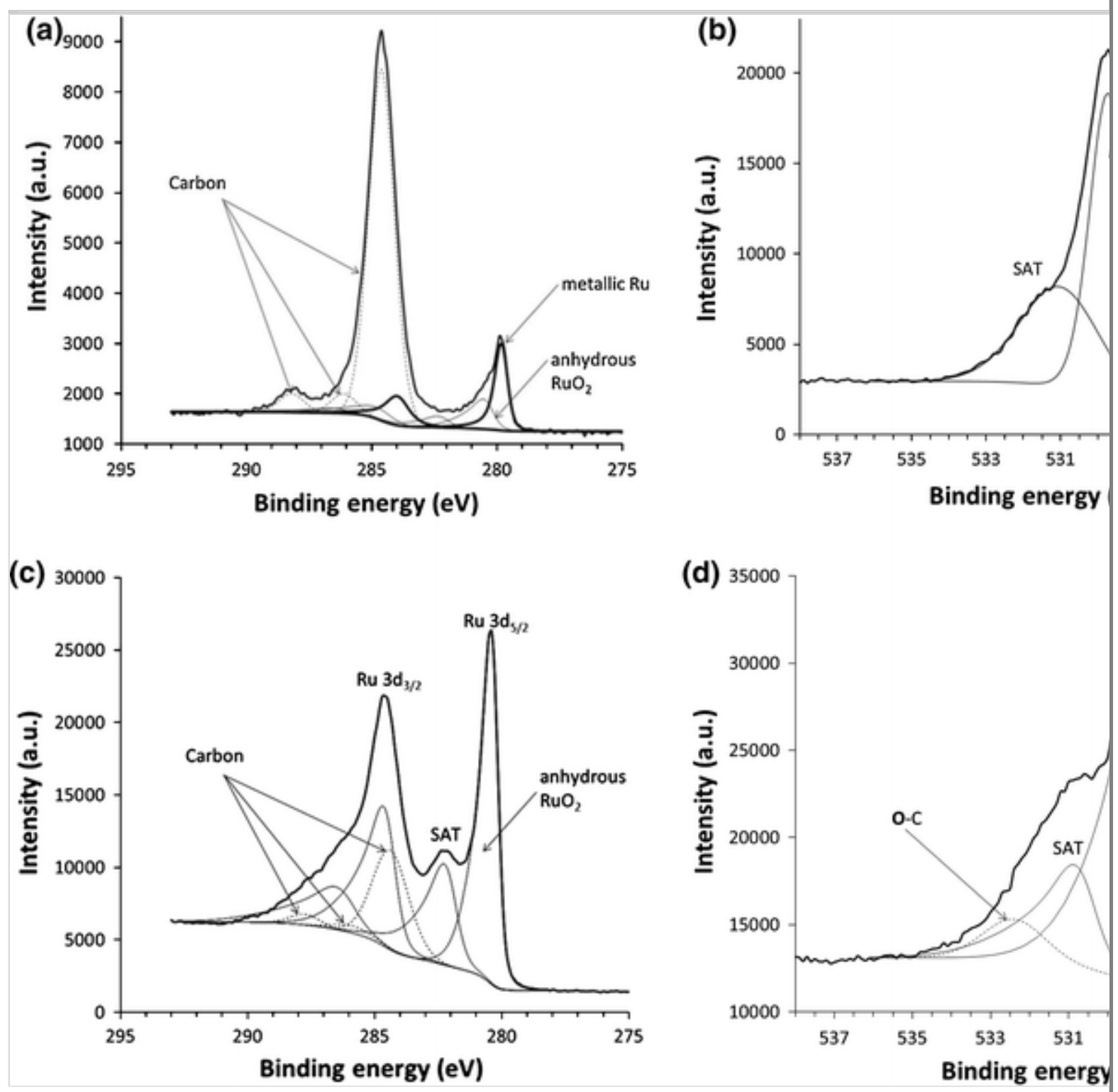
To conclude, the XPS analysis of Ru deposit on pre-oxidized SS pieces showed that it is characteristic of anhydrous $\mathrm{RuO}_{2}$ species in a major part of the cases with the possibility of Ru metal at high temperature. The difference of colour observed within a quartz tube seems to be linked only to the thickness of the deposit (lower thickness deposit is green near the exit of the device and higher thickness deposit is black in the gradient profile after the exit of the furnace). Thus, the surface analyses tend to show that all the $\mathrm{Ru}$ deposits along the thermal tube present in our experiments are forms of the $\mathrm{RuO}_{2}$ species, similarly to previous works $[19,21,22,23]$.

\section{Conclusions}

In the frame of the OECD STEM project, small scale-experiments were performed on the START set-up to better understand ruthenium chemical behaviour in the RCS with SA oxidative conditions.

Our experimental results are quite consistent with previous works, i.e. ruthenium tetroxide is formed in air/steam by oxidation of ruthenium dioxide and a relevant amount, which mainly depends on thermal gradient, residence time and gas composition is measured at low temperature as well as a fraction in aerosol form.

Our experiments have shown that, whatever the tube material $(\mathrm{Q} / \mathrm{SS})$, the thermal profile (abrupt/smooth) and the gaseous mixture (with or without steam in the mixture), the major part of the vaporized Ru was deposited along the thermal gradient tube ( $>95 \%$ of the "crucible" vaporized Ru mass) at the end of the tests after consecutive vaporization and revaporization phases, consistent with literature data. So, the total Ru transported downstream (gaseous and aerosols, including $\mathrm{Ru}$ deposited on the dipping tube of the first liquid trap) represents about a few percent of the Ru mass vaporized (1.5 up to $4.5 \%$ ), mainly under gaseous form.

After a detailed characterization of the heating phase with argon, the $\mathrm{Ru}$ vaporization kinetics in the oxidant test was found to be linear for all the studied gaseous mixtures (steam/air) and can be considered as steam 
content dependent. The dry air condition promotes the vaporization of $\mathrm{RuO}_{2}$ from the crucible at $1200{ }^{\circ} \mathrm{C}$.

During the vaporization phase from the crucible with reagent, the long duration tests pointed out the existence of transient phenomena in the short term (first hour(s)), whatever the gaseous mixture composition, that were never observed until now and thus reinforce the need to perform quite long tests (few hours). The abrupt thermal profile increases the total $\mathrm{Ru}$ amount transported at the outlet during the vaporization processes compared to a smooth one. In addition, it also favours $\mathrm{RuO}_{2}$ particle formation (aerosols) in the gaseous phase whereas there is only $\mathrm{Ru}$ gaseous species with a smooth gradient profile. The precise steam effect on the total $\mathrm{Ru}$ transported could not be clearly determined in our vaporization tests. However, the large presence of steam does not change the phenomenology and could favor the $\mathrm{Ru}$ gaseous transport; this point needs confirmation by additional tests.

During the revaporization phase of the $\mathrm{Ru}$ deposited on the transport tube, $\mathrm{Ru}$ was transported mainly as a gaseous form to the tube outlet and no transient phenomenon was observed. Contrary to the vaporization tests, there is a possible gas composition effect linked to the tube material on the $\mathrm{Ru}$ transported during the revaporization tests: $\mathrm{Ru}$ transport is increased with an excess of air for quartz tube (abrupt profile) and with an excess of steam for SS tube (abrupt profile).

Moreover, this work underlines the importance of the gaseous mixture composition during the Ru deposit formation and consequently on the revaporization phase. This study allowed the measurement of the deposit profiles depending on the temperature wall and did not reveal a significant effect of the gas mixture (with or without steam) on the $\mathrm{Ru}$ deposit profile in the quartz tube.

Finally, in this study on the transport of ruthenium in conditions similar to those prevailing in the RCS, the total Ru transported at the tube outlet after vaporization and revaporization long duration experiments led up to $4.5 \%$ of the "crucible" $\mathrm{Ru}$ vaporized mass (in the tests conditions). With experimental conditions representative of a PWR 
severe accident (Stainless Steel, abrupt thermal profile, steam in excess and an outlet temperature at about $170{ }^{\circ} \mathrm{C}$ ), revaporization phase led to a similar gaseous $\mathrm{Ru}$ release at the transport tube outlet as the one observed during the vaporization phase $(\sim 1.2 \%$ of the "crucible" vaporized $\mathrm{Ru}$ mass). However, this is not the maximum reachable value because the revaporization phase was not finished at the end of the experiment (only $12 \mathrm{~h}$ of revaporization). During a hypothetical nuclear accident, the vaporization phase is a short term phenomenon while the revaporization phase is potentially quite a long, continuous process. Further investigations on ruthenium revaporization processes with more oxidizing prototypic conditions, SS material and an improvement of the test protocol are currently carried out in the frame of the OECD STEM2 project [36].

These experimental results allow a better understanding of the Ruthenium transport in the RCS and will be used to implement an accurate modelling in the ASTEC code. This model will also allow improved source term assessments because, in terms of nuclear safety, a deeper understanding of Ru chemistry will be necessary for better severe accident countermeasures if needed.

\section{Acknowledgements}

The authors acknowledge the OECD/NEA/CSNI hosting the STEM project and the STEM project partners: Electricité De France, Canadian National Laboratories (Canada), Teknologian tutkimuskeskus VTT (Finland), Nuclear Research Institute (Czech Republic), Gesellschaft für Anlagen-und Reaktorsicherheit (Germany), Nuclear Regulatory Commission (USA), Korea Atomic Energy Research Institute and Korea Institute for Nuclear Safety (South Korea). The authors also thank the CNRS Grenoble LEPMI for Raman spectrometry (A. Kasperski), the CNRS Villeurbanne (ISA) for the measurements of Ru deposit with the alkaline fusion method (L. Ayouni) and K. Boucault, C. Gomez, N. Monchalin, S. Souvi, L. Cantrel and C. Mun from IRSN for their technical contribution and fruitful discussion.

\section{References}


1. Auvinen A, Brillant G, Davidovich N, Dickson R, Ducros G, Dutheillet Y, Giordano P, Kunstar M, Kärkelä T, Mladin M, Pontillon Y, Séropian C, Vér N (2008) Progress on ruthenium release and transport under air ingress conditions. Nucl Eng Des 238 (12):3418-3428. https://doi.org/10.1016/j.nucengdes.2008.07.010

2. Powers DA, Kmetyk LN, Schmidt RC (1994) A review of the technical issues of air ingression during severe reactor accidents. Nuclear Regulatory Commission, Div. of Systems Research, Sandia National Labs, Albuquerque, NM, Washington, DC

3. Pontillon Y, Ducros G (2010) Behaviour of fission products under severe PWR accident conditions. The VERCORS experimental programme-part 3: release of low-volatile fission products and actinides. Nucl Eng Des 240(7):1867-1881. https://doi.org/10.1016/j.nucengdes.2009.06.025

4. Pontillon Y, Ducros G, Malgouyres PP (2010) Behaviour of fission products under severe PWR accident conditions VERCORS experimental programme - part 1: general description of the programme. Nucl Eng Des 240(7):1843-1852. https://doi.org/10.1016/j.nucengdes.2009.06.028

5. Gallais-During A, Bonnin J, Malgouyres PP, Morin S, Bernard S, Gleizes B, Pontillon Y, Hanus E, Ducros G (2014) Performance and first results of fission product release and transport provided by the VERDON facility. Nucl Eng Des 277:117-123.

https://doi.org/10.1016/j.nucengdes.2014.05.045

6. Hunt CEL, Cox DS, Liu Z, Keller NA, Barrand RD, O'Connor RF, Iglesias FC (1991) Ruthenium release in air. In: Annual International Conference-Canadian Nuclear Association, pp 290 $-295$

7. Leggett RW (2012) The biokinetics of ruthenium in the human body. Radiat Prot Dosim 148(4):389-402.

https://doi.org/10.1093/rpd/ncr197 
8. Snipes MB, Kanapilly GM (1983) Retention and dosimetry of ${ }^{106} \mathrm{Ru}$ inhaled along with inert particles by fischer-344 rats. Health Phys 44(4):335-348

9. Mun C, Cantrel L, Madic C (2006) Review of literature on ruthenium behavior in nuclear power plant severe accidents. Nucl Technol 156(3):332-346

10. Malá H, Rulík P, Bečková V, Mihalík J, Slezáková M (2013) Particle size distribution of radioactive aerosols after the Fukushima and the Chernobyl accidents. J Environ Radioact 126:92-98. https://doi.org/10.1016/j.jenvrad.2013.07.016

11. Mun C, Cantrel L, Madic C (2007) Study of $\mathrm{RuO}_{4}$ decomposition in dry and moist air. Radiochim Acta 95(11):643 -656. https://doi.org/10.1524/ract.2007.95.11.643

12. Mun C, Cantrel L, Madic C (2008) Radiolytic oxidation of ruthenium oxide deposits. Nucl Technol 164(2):245-254

13. Kajan I, Lasseson H, Persson I, Ekberg C (2016) Interaction of ruthenium tetroxide with surfaces of nuclear reactor containment building. J Nucl Sci Technol 53(9):1397-1408. https://doi.org/10.1080/00223131.2015.1120245

14. Klein-Heßling W, Sonnenkalb M, Jacquemain D, Clément B, Raimond E, Dimmelmeier H, Azarian G, Ducros G, Journeau C, Puebla LEH, Schumm A, Miassoedov A, Kljenak I, Pascal G, Bechta S, Güntay S, Koch MK, Ivanov I, Auvinen A, Lindholm I (2014) Conclusions on severe accident research priorities. Ann Nucl Energy 74:4-11. https://doi.org/10.1016/j.anucene.2014.07.015

15. Miradji F, Cousin F, Souvi S, Vallet V, Denis J, Tanchoux V, Cantrel L (2015) Modelling of Ru behaviour in oxidative accident conditions and first source term assessments. In: The 7th European Review Meeting on Severe Accident Research (ERMSAR), Marseille, France, pp 24-26 
16. Vér N, Matus L, Kunstár M, Osán J, Hózer Z, Pintér A (2010) Influence of fission products on ruthenium oxidation and transport in air ingress nuclear accidents. J Nucl Mater 396(2-3):208-217. https://doi.org/10.1016/j.jnucmat.2009.11.008

\section{Vér N, Matus L, Pintér A, Osán J, Hózer Z (2012) Effects of} different surfaces on the transport and deposition of ruthenium oxides in high temperature air. J Nucl Mater 420(1):297-306. https://doi.org/10.1016/j.jnucmat.2011.09.030

18. Backman U, Lipponen M, Auvinen A, Tapper U, Zilliacus R, Jokiniemi JK (2005) On the transport and speciation of ruthenium in high temperature oxidising conditions. Radiochim Acta 93(5):297 -304. https://doi.org/10.1524/ract.93.5.297.64280

19. Kärkelä T, Backman U, Auvinen A, Zilliacus R, Lipponen M, Kekki T, Tapper U, Jokiniemi J (2007) Experiments on the behaviour of ruthenium in air ingress accidents - final report. SARNET-ST-P58, VTT Processes, Espoo, Finland

20. Kärkelä T, Vér N, Haste T, Davidovich N, Pyykönen J, Cantrel L (2014) Transport of ruthenium in primary circuit conditions during a severe NPP accident. Ann Nucl Energy 74:173-183. https://doi.org/10.1016/j.anucene.2014.07.010

21. Kajan I, Kärkelä T, Tapper U, Johansson LS, Gouëllo M, Ramebäck H, Holmgren S, Auvinen A, Ekberg C (2017) Impact of $\mathrm{Ag}$ and NOx compounds on the transport of ruthenium in the primary circuit of nuclear power plant in a severe accident. Ann Nucl Energy 100:9-19. https://doi.org/10.1016/j.anucene.2016.10.008

22. Kärkelä T, Kajan I, Tapper U, Auvinen A, Ekberg C (2017) Ruthenium transport in an RCS with airborne CsI. Prog Nucl Energy 99:38-48. https://doi.org/10.1016/j.pnucene.2017.04.019

23. Kajan I, Kärkelä T, Auvinen A, Ekberg C (2017) Effect of nitrogen compounds on transport of ruthenium through the RCS. J 
Radioanal Nucl Chem 311(3):2097-2109.

https://doi.org/10.1007/s10967-017-5172-7

24. START Ruthenium tests are part of the OECD/NEA Source Term Evaluation and Mitigation (STEM) project. (https://oecdnea.org/jointproj/stem.html)

25. Chatelard P, Belon S, Bosland L, Carénini L, Coindreau O, Cousin F, Marchetto C, Nowack H, Piar L, Chailan L (2016) Main modelling features of the ASTEC V2.1 major version. Ann Nucl Energy 93:83-93. https://doi.org/10.1016/j.anucene.2015.12.026

26. Larsen RP, Ross LE (1959) Spectrophotometric determination of ruthenium. Anal Chem 31(2):176-178.

https://doi.org/10.1021/ac60146a004

27. Morgan DJ (2015) Resolving ruthenium: XPS studies of common ruthenium materials. Surf Interface Anal 47(11):1072 -1079. https://doi.org/10.1002/sia.5852

28. Huang YS, Pollak FH (1982) Raman investigation of rutile $\mathrm{RuO}_{2}$. Solid State Commun 43(12):921-924.

https://doi.org/10.1016/0038-1098(82)90930-9

29. Musić S, Popovi S, Maljkovi M, Furi K, Gajovi A (2002) Influence of synthesis procedure on the formation of $\mathrm{RuO}_{2}$. Mater Lett 56(5):806-811. https://doi.org/10.1016/s0167-577x(02)00618-3

30. Griffith WP (1968) Raman spectra of ruthenium tetroxide and related species. J Chem Soc A.

https://doi.org/10.1039/j19680001663

31. McDowell RS, Asprey LB, Hoskins LC (1972) Vibrational spectrum and force field of ruthenium tetroxide. J Chem Phys 56 (11):5712-5721. https://doi.org/10.1063/1.1677093

32. Chan HYH, Takoudis CG, Weaver MJ (1997) High-pressure oxidation of ruthenium as probed by surface-enhanced raman and 
X-ray photoelectron spectroscopies. J Catal 172(2):336-345. https://doi.org/10.1006/jcat.1997.1841

33. Bhaskar S, Dobal PS, Majumder SB, Katiyar RS (2001) X-ray photoelectron spectroscopy and micro-Raman analysis of conductive $\mathrm{RuO}_{2}$ thin films. J Appl Phys 89(5):2987-2992. https://doi.org/10.1063/1.1337588

34. Kim KS, Winograd N (1974) X-Ray photoelectron spectroscopic studies of ruthenium-oxygen surfaces. J Catal 35(1):66-72. https://doi.org/10.1016/0021-9517(74)90184-5

35. Mun C, Ehrhardt JJ, Lambert J, Madic C (2007) XPS investigations of ruthenium deposited onto representative inner surfaces of nuclear reactor containment buildings. Appl Surf Sci 253 (18):7613-7621. https://doi.org/10.1016/j.apsusc.2007.03.071

36. Mun C, Bosland L, Cantrel L, Colombani J, Leroy O, Ohnet MN, Albiol T (2015) OECD STEM Project and its follow-up STEM2. In: International Iodine Workshop, Marseille (France) 